\title{
Neuronal Subset-Specific Migration and Axonal Wiring Mechanisms in the Developing Midbrain Dopamine System
}

\author{
Sara Brignani and R. J. Pasterkamp* \\ Department of Translational Neuroscience, Brain Center Rudolf Magnus, University Medical Center Utrecht, Utrecht, \\ Netherlands
}

The midbrain dopamine (mDA) system is involved in the control of cognitive and motor behaviors, and is associated with several psychiatric and neurodegenerative diseases. mDA neurons receive diverse afferent inputs and establish efferent connections with many brain areas. Recent studies have unveiled a high level of molecular and cellular heterogeneity within the mDA system with specific subsets of mDA neurons displaying select molecular profiles and connectivity patterns. During mDA neuron development, molecular differences between mDA neuron subsets allow the establishment of subsetspecific afferent and efferent connections and functional roles. In this review, we summarize and discuss recent work defining novel mDA neuron subsets based on specific molecular signatures. Then, molecular cues are highlighted that control mDA neuron migration during embryonic development and that facilitate the formation of selective patterns of efferent connections. The review focuses largely on studies that

OPEN ACCESS

Edited by:

Sandra Blaess,

University of Bonn, Germany

Reviewed by:

Lia Panman,

Medical Research Council,

United Kingdom

Yu-Qiang Ding,

Tongji University, China

*Correspondence:

R. J. Pasterkamp

r.j.pasterkamp@umcutrecht.nl

Received: 08 May 2017

Accepted: 20 June 2017

Published: 10 July 2017

Citation:

Brignani S and Pasterkamp RJ (2017) Neuronal Subset-Specific

Migration and Axonal Wiring Mechanisms in the Developing

Midbrain Dopamine System.

Front. Neuroanat. 11:55.

doi: 10.3389/fnana.2017.00055 show differences in these mechanisms between different subsets of mDA neurons and for which in vivo data is available, and is concluded by a section that discusses open questions and provides directions for further research.

Keywords: midbrain dopamine system, development, substantia nigra, ventral tegmental area, neuronal subsets, striatum, axon guidance, migration

\section{INTRODUCTION}

The dopamine system of the ventral midbrain (mDA system) can be subdivided into three main nuclei: substantia nigra pars compacta (SNc, A9), ventral tegmental area (VTA, A10), and retrorubral field (RRF, A8). Dopaminergic neurons of the $\mathrm{mDA}$ system are characterized by the synthesis and release of the neurotransmitter dopamine, and the expression of tyrosine hydroxylase $(\mathrm{TH})$ and the dopamine transporter (DAT). SNc mDA neurons contribute to the control of voluntary movement and their selective degeneration is a pathological hallmark of Parkinson's disease (Kalia and Lang, 2015). VTA mDA neurons play a role in positive and negative reinforcement, decision making, working memory, and aversion (for a review see, Morales and Margolis, 2017). Dopamine imbalance in VTA mDA neurons has been implicated in schizophrenia, attention deficit hyperactivity disorder (ADHD), obsessive-compulsive disorder (OCD), addiction, and depression (Winterer and Weinberger, 2004; Faraone et al., 2005; Chaudhury et al., 2012; Milton and Everitt, 2012). Their important physiological functions and implication in human disease has triggered an enormous interest in understanding the development and function of mDA neurons. 
It is becoming clear that neurons within the anatomically defined SNc and VTA nuclei are not homogeneous. Rather multiple distinct $\mathrm{mDA}$ neuron subsets exist within and across the boundaries of the SNc and VTA. For example, subsets that differ by specific molecular markers, by afferent inputs, and by the brain structures they innervate. To understand how these differences arise, the developmental origin and molecular programs in mDA neuron subsets are studied intensively. It is likely, and in part known, that different $\mathrm{mDA}$ neuron subsets express specific molecular cues that allow subset-specific differentiation, migration and axon guidance.

In this review, we first summarize and discuss our current knowledge of the neuron subsets present in the mDA system. Then, molecular mechanisms are highlighted that aid $\mathrm{mDA}$ neurons in migrating to their final position in the midbrain and that allow the formation of selective patterns of efferent connections. We will focus mainly on studies that show differences in these mechanisms between different subsets of mDA neurons and for which in vivo data is available. For other studies on this topic which are not covered here we refer to other reviews (Van den Heuvel and Pasterkamp, 2008; Prestoz et al., 2012). The review is concluded by a section that discusses open questions and provides directions for further research.

\section{NEURONAL DIVERSITY IN THE mDA SYSTEM}

\section{Identification of mDA Neuron Subsets}

Historically, anatomical and cytological features have been used to subdivide mDA neurons into subsets. According to this approach, SNc can be divided into a ventral and dorsal tier, whereas the VTA includes the parabrachial pigmented nucleus (PBP), the paranigral nucleus $(\mathrm{PN})$, the caudal linear nucleus (CLi), the interfascicular nucleus (IF), and the rostral linear nucleus of the raphe (RLi) (Fu et al., 2012) (Figures 1A,B). Molecular markers exclusively expressed by single mDA subsets have not been identified yet. However, the expression of a few genes is commonly used to molecularly distinguish larger mDA domains. For example, the glycosylated active form of the dopamine transporter (glyco-DAT) and the G-protein-gated inwardly rectifying $\mathrm{K}^{+}$channel (Girk2) are more abundantly expressed by SNc and dorso-lateral VTA mDA neurons (Schein et al., 1998; Thompson et al., 2005; Afonso-Oramas et al., 2009), while Calbindin 1 (Calb1) expression is enriched in mDA neurons of the VTA and of the dorsal tier of the SNc (Thompson et al., 2005; Di Salvio et al., 2010; Fu et al., 2012). Within the VTA, the transcription factor Otx2 strongly labels ventro-medial mDA neurons and gradually deceases in the central and dorso-lateral VTA (Simeone et al., 2011).

The development and use of single-cell RNA approaches has recently led to a further subdivision of the SNc and VTA on basis of molecular features (Poulin et al., 2014; La Manno et al., 2016). In one study, mDA neurons were collected at postnatal day 4 (P4) using a dopaminergic neuron-specific Cre-driver mouse line (Slc6a3-Cre) crossed with a TdTomato Cre-reporter mouse. qPCR was performed on single mDA neurons to determine expression levels of 96 selected genes. An unbiased coefficient similarity hierarchical clustering analysis allowed the clustering of cells in groups on basis of their gene expression profiles. This method identified two main cell clusters (cluster 1 and cluster 2). On basis of their expression profiles, mDA neurons from cluster 1 were more similar to SNc neurons, whereas neurons from cluster 2 had an expression profile related to VTA neurons. The two clusters were subsequently subdivided in two and four cell types, respectively (i.e., 1A, B, 2A-D) (Poulin et al., 2014). Another study analyzed P21 mDA neurons, collected using the same genetic strategy as described above, by single-cell RNA sequencing (RNAseq). In this second study, five cell types were identified (SNC, VTA1-4) (La Manno et al., 2016).

By using a set of marker genes (listed in different groups in Figure 2), we compared the five cell types reported by La Manno et al. (2016) with the six cell types identified at P4 by Poulin et al. (2014) (Figure 2). Interestingly, each of the five cell types identified at P21 has a corresponding cell type identified at P4. This suggests that the mDA system can be subdivided in (at least) five cellular subsets, each of which is characterized by a specific molecular signature. Moreover, the analysis indicates that these five neuronal subsets are already in place at P4. One cluster identified at P4 (2C) does not correspond to a cluster found at $\mathrm{P} 21$. This cluster expresses genes shared by all populations of cluster 2 (e.g., Calb1, Cck, and Slc17a6), but none of the markers that define specific cell types within cluster 2 [Slc32a1 (2A), Adcyap1 (2B), and Vip (2D)] (Poulin et al., 2014). This group of mDA neurons (2C) might be composed of neurons that are not completely mature at $\mathrm{P} 4$, and that acquire an adult phenotype at later stages, becoming part of one of the other subsets of cluster 2 .

Comparison of the dopaminergic subnuclei as defined on basis of anatomical features with the location of the five subsets described above (SNc/1A, VTA1/1B, VTA2/2B, VTA3/2D, VTA4/2A) shows that cell types $1 \mathrm{~A}$ and $1 \mathrm{~B}$ mainly correspond to the ventral and dorsal parts of the $\mathrm{SNc}$, respectively (Figure 1B). In Parkinson's disease, $\mathrm{mDA}$ neurons of the ventral tier are known to be particularly vulnerable and in line with this cluster $1 \mathrm{~A}$ is more selectively affected in a mouse model of Parkinson's disease, as compared to cluster 2B (Poulin et al., 2014). The VTA contains neurons from different clusters (2A, 2B, 2C, and part of 1B) (Figure 1B). Cluster $2 \mathrm{~B}$ is selectively positive for Grp and is positioned mainly in the PN and IF, which are nuclei with $\mathrm{mDA}$ neurons that project their axons to the NAc (Poulin et al., 2014; La Manno et al., 2016). In line with these results, an independent study demonstrated that VTA mDA neurons projecting to the NAc are Grp ${ }^{+}$(Ekstrand et al., 2014). The most caudal $\mathrm{VIP}^{+}$cluster (2D) is restricted to the dorsal raphe nucleus (DR) and periaqueductal gray (PAG) (Poulin et al., 2014; La Manno et al., 2016). Immunostaining for Vip, which is expressed by $\mathrm{mDA}$ axons, demonstrates that these mDA neurons establish connections with the stria terminalis and the amygdala (Poulin et al., 2014), indicating that molecular profiles are correlated with specific projection patterns. None of the identified cell-types is located in the RRF, even though the Slc6a3-Cre mouse line efficiently labels this structure (Bäckman et al., 2006). A possible explanation for this observation is that the RRF may host relatively small cell clusters which are not 
A

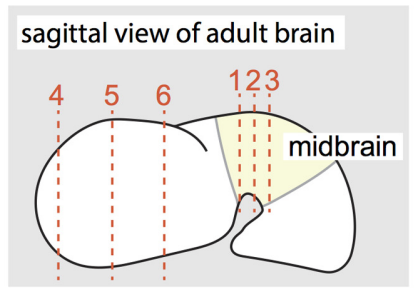

B
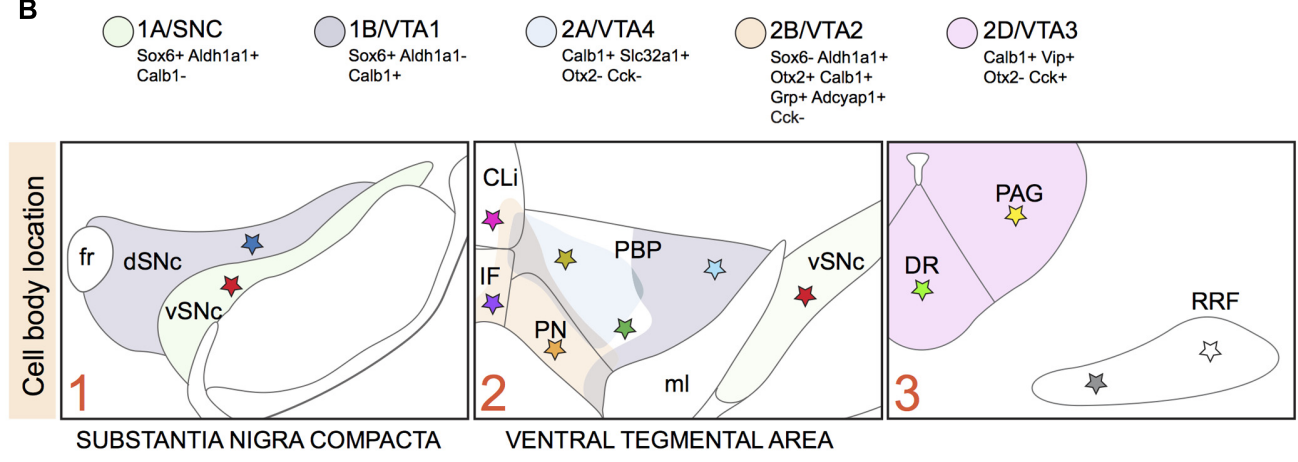

C

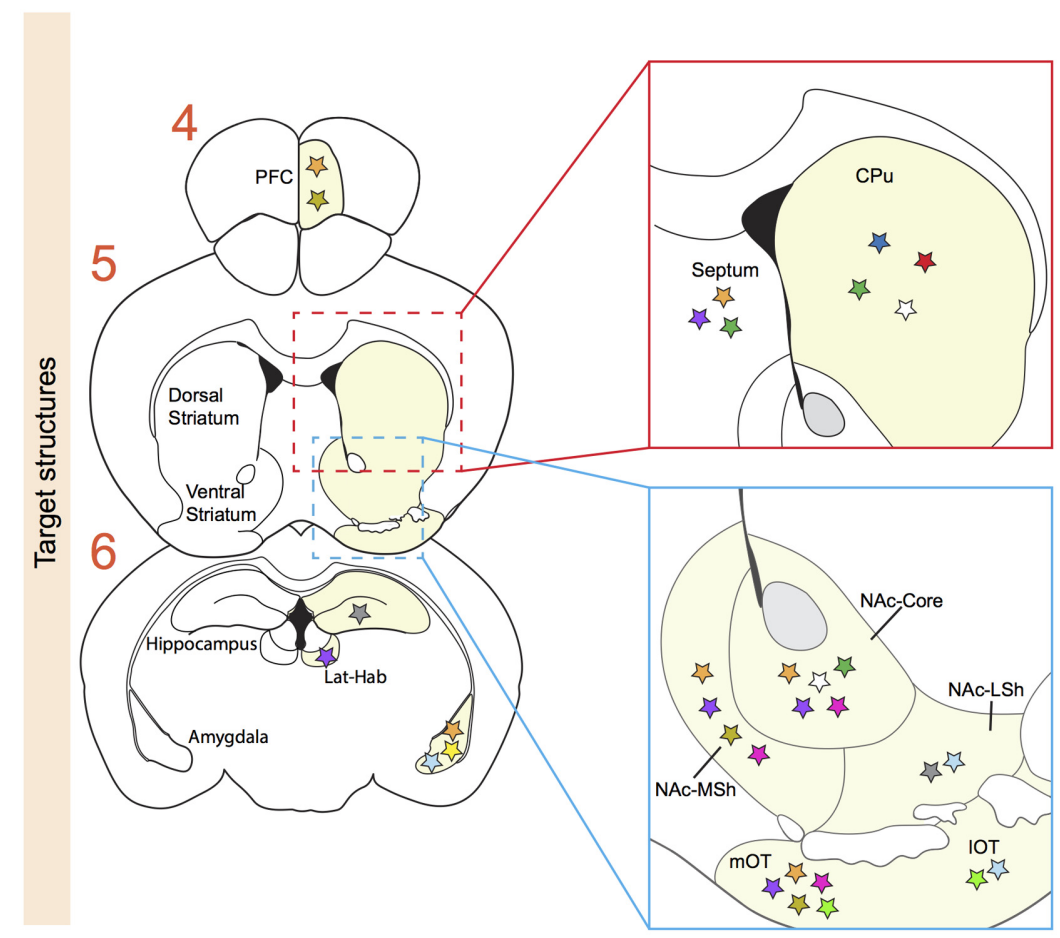

FIGURE 1 | Projection areas of molecularly defined subsets of dopaminergic neurons in the adult brain. (A) Sagittal representation of an adult brain. Numbered dotted lines refer to coronal views in (B,C). (B) Overlap of anatomically defined domains (dSNc, vSNc, PBP, PN, CLi, and IF) and mDA neuron clusters identified by specific molecular signatures (1AVSNC, 1BNTA1, 2ANTA4, 2BNTA2, and 2DNTA3; see Figure 2). Each cluster is defined by a few distinctive molecular markers and by unique colors. Colored stars represent mDA neuron subsets projecting to specific brain structures in C. (C) A colored star in $\mathrm{C}$ represents the brain region innervated by a specific mDA subset identified by a colored star in B. Stars with the same color represent mDA subsets and their target structures, respectively (Gasbarri et al., 1996; Ikemoto, 2007; Lammel et al., 2008; Matsuda et al., 2009; Stamatakis et al., 2013; Poulin et al., 2014; Aransay et al., 2015; Khan et al., 2017). vSNc, SNc ventral tier; dSNc, SNc dorsal tier; PBP, parabrachial pigmented nucleus; PN, paranigral nucleus; IF, interfascicular nucleus; CLi, caudal linear nucleus; DR, dorsal raphe nucleus; PAG, periaqueductal gray; RRF, retrorubral field; fr, fasciculus retroflexus; ml, medial lemniculus; PFC, medial prefrontal cortex; Lat-Hab, lateral habenula; CPu, caudate-putamen; NAc, nucleus accumbens; MSh, medial shell; LSh, lateral shell; mOT, medial olfactory tubercle; IOT, lateral olfactory tubercle. 

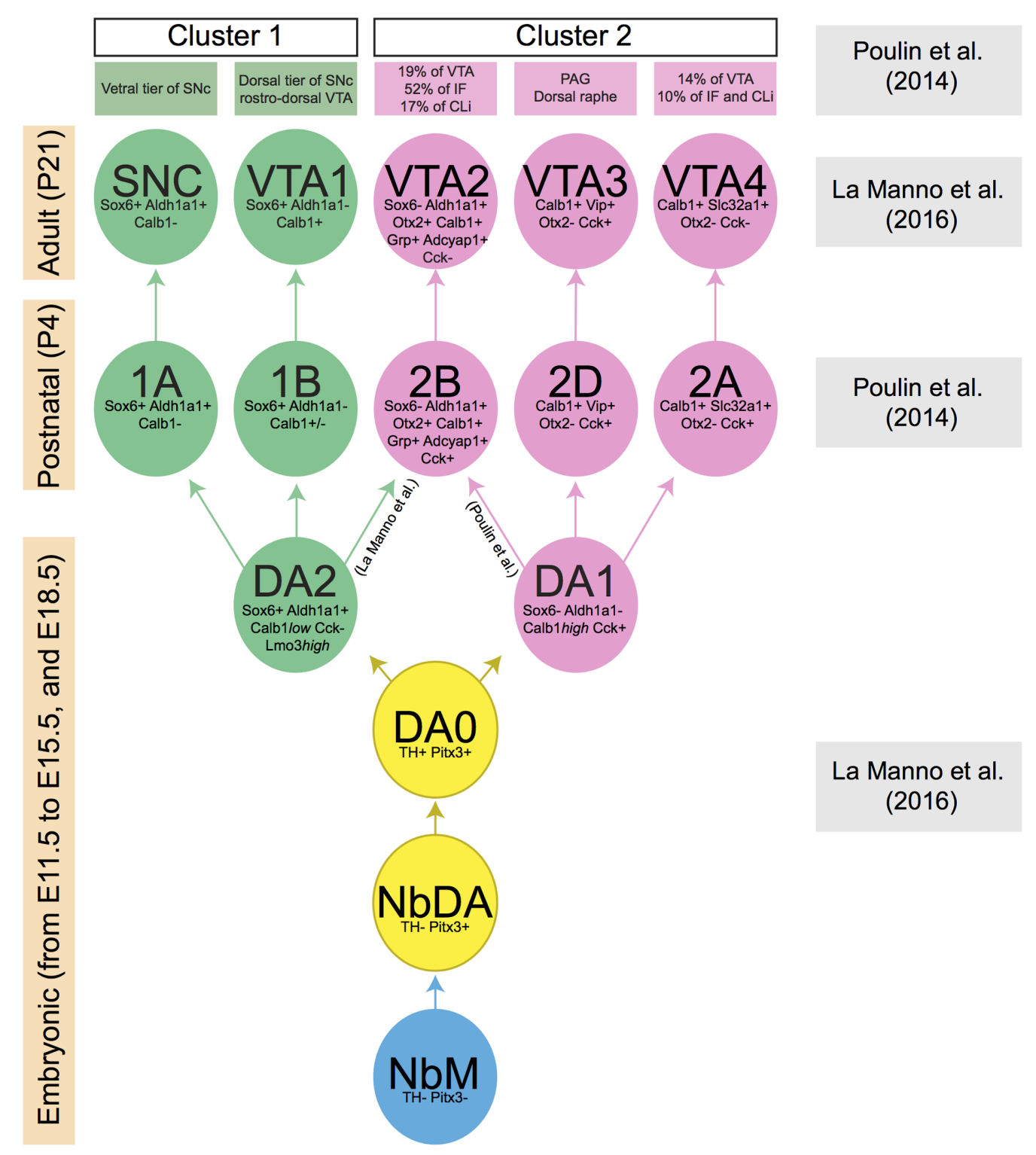

La Manno et al. (2016)

FIGURE 2 | Lineage of mDA neuron subsets obtained by the comparison of two recent publications (Poulin et al., 2014; La Manno et al., 2016). Each mDA neuron cluster is defined by a few distinctive molecular markers which are indicated in the cluster. Boxes at the left indicate the developmental stage at which a specific collection of clusters is present (embryonic, postnatal, and adult phases). Boxes at the right indicate the publication that generated the data at specified time points. The green and pink boxes at the top list the anatomically defined domains in SNc or VTA in which the molecularly defined mDA clusters are positioned. During embryonic development, a group of mDA precursors ( $\mathrm{NbM}$, blue circle) gives rise to two consecutive groups of immature mDA subsets (NbDA and DAO, yellow circles). Then, two clusters of mature mDA neurons (DA1 and DA2, pink and green circles, respectively) originate from DA0. DA1 is the ancestor of all clusters represented in pink circles, whereas DA2 is the ancestor of all clusters represented in green circles. Data are not conclusive on the origin of mDA cluster 2BNTA2, which may originate from DA1 or DA2. Calb1 is variably expressed by mDA neurons of cluster 1B (indicated in figure as Calb1+/-).

identified by the currently applied RNAseq and data analysis methods. It should also be noted that Poulin et al. (2014) and La Manno et al. (2016) used different techniques to identify subsetspecific molecular profiles. It is therefore likely that in future studies additional subsets of $\mathrm{mDA}$ neurons are identified.

One of the studies described above also performed an unbiased analysis based on single-cell RNAseq data obtained from embryonic ventral midbrain tissue (collected from E11.5 to
E15.5, and at E18.5). This procedure allowed the identification of a group of $\mathrm{mDA}$ precursors (medial neuroblasts, $\mathrm{NbM}$ ), two immature mDA cell-types (NbDA and DA0), and two clusters of mature mDA neurons (DA1 and DA2) (La Manno et al., 2016). At E18.5, DA2 neurons express Aldh1a1, Sox6, and Calb1low which, in the adult brain, label three cell-subsets (1A/SNC, 1B/VTA1, 2B/VTA2). This suggests that DA2 neurons may be a common ancestor of these three groups (Figure 2), whereas DA1 may give 
rise to 2D/VTA3 and 2A/VTA4 (La Manno et al., 2016). However, it is important to note that according to the study of Poulin et al. (2014) the 2B/VTA2 subset belongs to cluster 2 and therefore it may derive from DA1 rather than DA2. Further work is needed to establish which ancestor (DA1 or DA2) generates the $\mathrm{mDA}$ subset 2B/VTA2. Interestingly, previous work has shown that the differentiation of the Calb1 $1^{+} /{\text {Aldh } 1 \mathrm{a} 1^{+}}^{+} \mathrm{mDA}$ neurons (which correspond to cluster $2 \mathrm{~B} / \mathrm{VTA} 2$ ) requires the expression of the transcription factor Otx2. The deletion of Otx2 gene from the midbrain at early developmental time points causes the depletion of the large majority of Calb1 ${ }^{+}$and Aldh1a1 ${ }^{+}$mDA neurons of the VTA, with only the mDA neurons of the dorso-lateral VTA $\left(\mathrm{Grik2}^{+}\right.$) surviving into adulthood (Di Giovannantonio et al., 2013).

The identification of mDA neuron subsets, their developmental origin and molecular signatures is important for understanding how subset-specific connectivity is established in the $\mathrm{mDA}$ system. For example, defining clusters of $\mathrm{mDA}$ precursors, and immature and mature mDA neurons ( $\mathrm{NbM}$, NbDA, DA0, DA1, and DA2) from the RNA expression analysis allows the identification of guidance genes expressed by these neuronal populations (Table 1) (La Manno et al., 2016). Members of different guidance cue families (e.g., Semaphorins, Ephrins) can be detected in different clusters. Guidance genes expressed at early developmental time points might play a role in the migration and/or axon guidance of $\mathrm{mDA}$ neuron subsets. In the following sections, we discuss what is currently known about the mechanisms that control mDA neuron migration and axon guidance, with a particular emphasis on subset-specific mechanisms.

\section{CELLULAR AND MOLECULAR MECHANISMS OF MDA NEURON MIGRATION}

\section{Distinct Origins and Migratory Routes of SNc and VTA mDA Neurons}

In mice, mDA neurons are born between E10.5 and E14.5. The majority of $\mathrm{SNc} \mathrm{mDA}$ neurons is born around E10.5,

TABLE 1 | Axon guidance genes expressed by dopaminergic precursors, and immature and mature mDA neurons.

\begin{tabular}{lllll}
\hline NbM & NbDA & DA0 & DA1 & DA2 \\
\hline DCC & DCC & DCC & DCC & DSCAM \\
Draxin & Draxin & Draxin & Draxin & Sema4D \\
Sema6C & Sema6C & Sema3F & & EphA5 \\
PlxnB1 & Nrp2 & Sema5B & & \\
Nrp2 & EphA5 & PlxnC1 & & \\
EphA3 & EfnB1 & EfnB2 & & \\
\hline
\end{tabular}

MRNA expression of axon guidance genes in mDA precursors (medial neuroblasts, $\mathrm{NbM}$ ), two immature $m D A$ cell-types (NbDA and DAO), and two clusters of mature mDA neurons (DA1 and DA2). These molecules might be involved in migration and/or axon guidance of mDA neuron subsets. Data are obtained from Linnarsson's lab webpage (www.linnarssonlab.org/ventralmidbrain) (see Figure 2). while neurogenesis of VTA mDA neurons is delayed and peaks around E11.5 (Bayer et al., 1995; Bye et al., 2012). Both neuron populations originate from progenitor cells positioned in the floor plate (FP) of the midbrain ventricular zone (VZ). $\mathrm{mDA}$ progenitors are divided into two subsets in the medial and the lateral zones of the FP. Around E8.5-E9.5, Sonic hedgehog (Shh) is exclusively expressed by medial mDA progenitors. However, at E11.5 Shh is no longer expressed in the medial zone, but is restricted to the lateral zone (Joksimovic et al., 2009; Blaess et al., 2011). This specific spatiotemporal pattern of Shh expression was recently exploited to perform fate mapping of $\mathrm{mDA}$ neurons and revealed that medial progenitors give rise to SNc mDA neurons, while lateral progenitors generate VTA mDA neurons (Blaess et al., 2011; Bodea et al., 2014). This observation was confirmed via immunostaining for Sox6 and Otx2/Nolz1, markers for both progenitors and mature mDA neurons of SNc and VTA, respectively. Sox $6^{+} / \mathrm{Otx} 2^{\text {weak }} / \mathrm{Nolz} 1^{-}$progenitors are located to the medial zone of the FP and Sox $6^{-} / \mathrm{Otx} 2^{\text {strong }} / \mathrm{Nolz}^{+}$ progenitors are confined to the lateral zone (Panman et al., 2014) (Figure 3A).

Following neurogenesis, post-mitotic mDA migrate from the FP to their final destination in the marginal zone (MZ). This migratory stage is characterized by two phases. During the first phase SNc and VTA mDA neurons undergo radial migration. Migrating VTA neurons $\left(\mathrm{Otx} 2^{+} / \mathrm{Nolz}^{+}\right)$originating from lateral progenitors are positioned laterally in the intermediate zone (IZ), while SNc neurons $\left(\right.$ Sox6 ${ }^{+}$) generated from medial progenitors are located medially in the IZ (Panman et al., 2014) (Figure 3A). Both VTA and SNc neurons show leading and trailing processes that are oriented radially, aligned with the fibers of radial glia-like (RGL) cells (Shults et al., 1990; Bodea et al., 2014). RGL fibers are thought to act as scaffolds for radially migrating mDA neurons, similar to the role of these cells in other regions of the developing nervous system (Marín et al., 2010). During the second phase of $\mathrm{mDA}$ neuron migration, $\mathrm{SNc} \mathrm{mDA}$ neurons migrate tangentially, which results in their movement from the medial toward the lateral MZ. This ultimately results in the formation of the characteristic wing-like $\mathrm{SNc}$ structure observed in the postnatal and adult brain (Figure 3A). It has been proposed that during tangential migration the leading processes of SNc mDA neurons follow tangential fibers, presumably axons originating from neurons positioned in the lateral midbrain (Kawano et al., 1995). The leading and trailing processes of VTA mDA neurons are almost exclusively oriented radially, and not tangentially. Therefore, it is thought that VTA neurons migrate mainly radially (Bodea et al., 2014).

The dopamine system is an extremely complex structure that extends in three dimensions, with the neurogenic FP positioned more medio-caudally than the two wings of the developing $\mathrm{SNc}$, which are protruding toward the rostro-lateral edges of the midbrain (Figure 3B). Data on the migration of $\mathrm{mDA}$ neurons along the anterior-posterior (A-P) axis is lacking and most of the studies on $\mathrm{mDA}$ neuron migration are performed on coronal sections at intermediate A-P levels of the mDA system. It is likely that the development of the mDA system not only involves radial and tangential migration of $\mathrm{mDA}$ neurons but also movement along the A-P axis. 
A

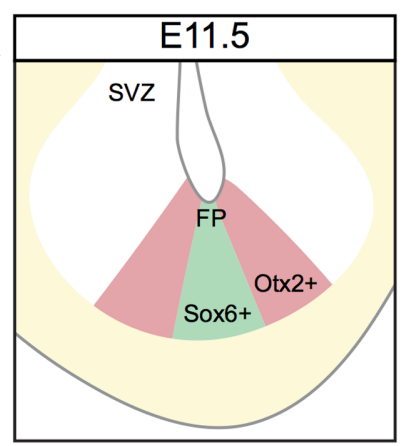

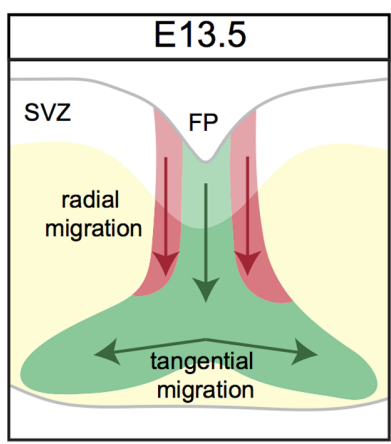

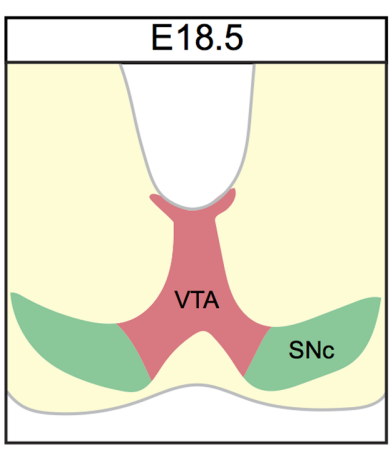

B

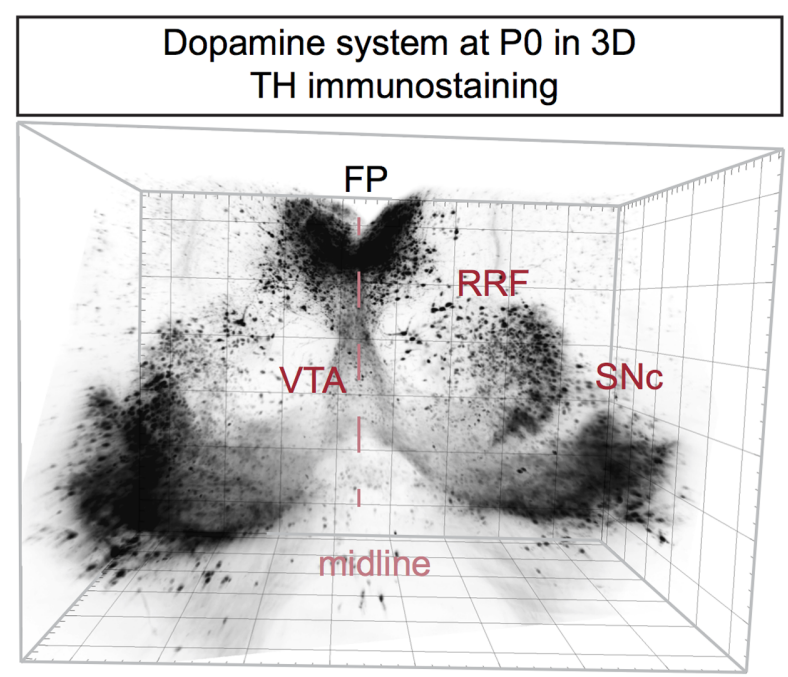

FIGURE 3 | Schematic representation of mDA neuron migration (A) and a 3D reconstruction of the dopamine system at postnatal day (P) 0 . (A) mDA neurons are generated in the subventricular zone (SVZ). SNc mDA progenitors are Sox6 $6^{+}$(green) and are positioned in the medial floor plate (FP). VTA mDA progenitors are Otx $2^{+}$(red) and are located in the lateral FP. First, mDA neurons migrate radially aligned along radial glia fibers. Next, only SNc mDA neurons migrate tangentially probably by using contralateral axons as a scaffold. At E18.5 mDA neuron migration is complete. (B) Coronal view of a 3D reconstruction of a P0 mouse brain immunostained using an anti-TH antibody (Brignani and Pasterkamp, unpublished data). Tissue was cleared using 3DISCO and imaged using Ultramicroscope lightsheet microscopy. The mDA system extends in three dimensions, with the neurogenic FP positioned caudally to the two wings of SNc. For other 3D views of the mDA system, see Figure 4.

\section{Guidance Molecules Involved in Radial Migration of mDA Neurons}

Radial migration of post-mitotic $\mathrm{mDA}$ neurons starts in the FP, continues in the IZ and concludes in the MZ. During this migratory process, post-mitotic cells differentiate and become $\mathrm{mDA}$ neurons. RGL cells are positioned in the ventricular zone, both in the FP and basal plate (BP), and extend their fibers to the pial surface. Recent work identifies three distinct RGL cell types in the midbrain ventricular zone: RGL1, present in both the FP and BP; RGL2, confined to the BP; and RGL3, restricted to the FP. RGL1 and RGL2 are found from E11.5 to E15.5 during radial migration of mDA neurons. RGL3 is only detected at E15.5 (La Manno et al., 2016). The functional role(s) of these RGL cells in the midbrain remains unknown. However, single-cell RNAseq data of the ventral midbrain shows that several axon guidance genes are expressed by the three types of RGL cells (La Manno et al., 2016) (Table 2). These axon guidance genes may be involved in the development of RGL cell fibers but also in guiding migrating $\mathrm{mDA}$ neurons toward the pial surface. Interestingly, while several axon guidance genes are expressed in all three RGL cell types, others are specific to one or two subtypes. Further work is needed to determine the role of the three RGL cell types and of the specific axon guidance molecules they express. However, it is tempting to speculate that specific RGL cells and their associated cues may be responsible for guiding different subsets of mDA neurons.

Although the specific RGL cell-derived molecules that regulate radial migration remain to be determined, meninges-derived chemokine signals have recently been shown to direct $\mathrm{mDA}$ neurons to the pial surface. Radially migrating $\mathrm{mDA}$ neurons express the chemokine receptor Cxcr4 from E10.5 to E14.5. Cxcr4 is a G protein-coupled receptor that is activated by the chemokine Cxcl12, which induces the phosphorylation of its C-terminal domain. Cxcl12 mRNA is expressed by meningeal 
cells during the period of mDA neuron migration (Yang et al., 2013; Bodea et al., 2014). In vitro meningeal explants attract migrating mDA neurons. This effect is blocked by administration of a Cxcr4 antagonist (Yang et al., 2013). Ectopic expression of Cxcl12 in the reticular formation in vivo causes $\mathrm{mDA}$ neurons to follow an abnormal route away from the midline in the IZ toward the ectopic Cxcl12 ${ }^{+}$cells (Yang et al., 2013). The speed and trajectory of migrating $\mathrm{mDA}$ neurons are intact when Cxcr4/Cxcl12 signaling is perturbed in vitro, indicating that other aspects of migration are controlled by this chemokine system (Bodea et al., 2014). Analysis of Cxcr4 and Cxcl12 KO mouse brains reveals that lack of $\mathrm{Cxcr} 4 / \mathrm{Cxcl} 12$ signaling in vivo causes an accumulation of $\mathrm{mDA}$ neurons in the IZ, in contrast to control conditions where these neurons reach the MZ (Bodea et al., 2014). Moreover, during the initial stage of radial migration (E11.5), mDA neurons lacking Cxcr4 have processes oriented in both radial and tangential directions, whereas most processes from neurons in wild-type mice show a radial orientation (Yang et al., 2013). At later developmental stages, defects are much milder in Cxcr4 KO mice and absent in Cxcl12 KO mice. This observation may hint at compensation of loss of chemokine

TABLE 2 | Canonical axon guidance genes expressed in three types of radial glia-like cells.

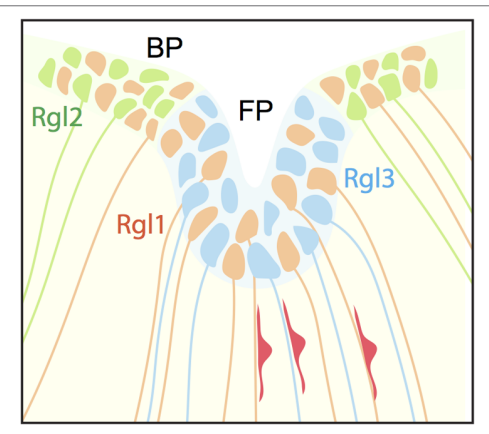

\begin{tabular}{c|cc}
\hline RGL1 & RGL2 & RGL3 \\
\hline Slit3 & Sema3B & Netrin1 \\
Sema3B & Sema5B & Slit1 \\
Sema5B & Sema6A & Slit2 \\
PlxnB1 & PlxnB1 & Sema3B \\
EphB1 & EphB1 & Sema5B \\
EphA3 & EphA3 & PlxnB1 \\
\hline EfnA4 & EphB3 & Nrp1 \\
EfnB1 & EfnA4 & EphA3 \\
& EfnB1 & EfnA4 \\
& & EfnB1 \\
\hline
\end{tabular}

Three populations of radial glia-like cells (RGL) have been identified in the midbrain ventricular zone. RGL extend their processes from the ventricular zone to the pial surface, functioning as scaffolds for the migrating $m D A$ neurons (red in the drawing). RGL1 is positioned in both the floor plate (FP) and the basal plate (BP). $R G L 2$ resides only in the BP, while RGL3 is found only in the FP. The three RGL populations express common and different guidance genes which are listed in the Table. Data was obtained from Linnarsson's lab webpage (www.linnarssonlab.org/ ventralmidbrain) and validated using the Allen Brain Atlas database (www.brainmap.org). Red indicates that the mRNA of the gene is detected in the Allen Brain Atlas at E13.5 and E15.5. Green indicates that signals are detected only at E13.5. Gray indicates that $m R N A$ is not detected. signaling by other molecular signals (Yang et al., 2013; Bodea et al., 2014).

The cell surface receptor DCC and its ligand Netrin1 also play a role in $\mathrm{mDA}$ neuron migration. DCC protein is expressed by $\mathrm{mDA}$ neurons during the period of their migration ( $\mathrm{Xu}$ et al., 2010). The Netrin 1 promoter is active in the ventral midbrain, both in the FP and in $\mathrm{TH}^{+}$nuclei (Li et al., 2014). DCC and Netrin 1 KO mice show ectopically (dorsally) positioned mDA neurons at $\mathrm{P} 0$, when $\mathrm{mDA}$ neuron migration has been completed (Xu et al., 2010; Li et al., 2014). Although the migration defects detected in DCC and Netrin1 KO mice are similar, how DCC-Netrin 1 signaling controls mDA neuron migration remains unknown. Interestingly, Netrin 1 is expressed by RGL cells in the FP (Table 2) and it is therefore tempting to speculate that RGL cell-derived Netrin 1 provides guidance for $\mathrm{DCC}^{+} \mathrm{mDA}$ neurons during their radial migration.

\section{Guidance Molecules Involved in Tangential Migration of mDA Neurons}

Following their radial migration, $\mathrm{SNc} \mathrm{mDA}$ neurons migrate tangentially, in part under control of Reelin and its receptors. Reelin controls the correct layering and polarization of different brain areas, such as the cortex and hippocampus (D'Arcangelo, 2014; Förster, 2014). It is a component of the extracellular matrix and signals via two receptors called low density lipoprotein receptor-related protein 8 (Apoer2) and very low density lipoprotein receptor (Vldlr). Binding of reelin to its receptors induces tyrosine phosphorylation of the intracellular signaling protein Dab1.

In the reeler mouse, an autosomal-recessive mouse mutant carrying a disrupted reelin gene, the SNc does not extend laterally at intermediate $\mathrm{A}-\mathrm{P}$ levels and $\mathrm{mDA}$ neurons accumulate in the VTA region. At rostral levels, the SNc develops normally and no significant change in the total number of $\mathrm{mDA}$ neurons is observed. Dab1 deficient mice (yotari mice) and double KO mice for Apoer2 and Vldlr show similar mDA neuron migration defects (Nishikawa et al., 2003; Kang et al., 2010; Bodea et al., 2014). This suggests that both receptors and Dab1 are mediators of reelin signaling in the midbrain. In line with these observations, both in vivo and in vitro experiments show that a subset of $\mathrm{SNc}$ neurons fails to orient their processes tangentially when reelin signaling is perturbed, while VTA mDA neurons are unaffected (Bodea et al., 2014). Reelin deficiency may alter the guidance scaffolds required for $\mathrm{mDA}$ neuron migration, but there is a lack of consensus on this hypothesis. Some studies report that tangential axons are intact in reeler mice at E15.5, whearas other work describes defects in the development of tangential axons in reeler and yotari mice as early as E14.5 (Nishikawa et al., 2003; Kang et al., 2010).

At E13.5, when $\mathrm{mDA}$ neurons are migrating both radially and tangentially, reelin mRNA is expressed by the red nucleus and absent from mDA neurons (Bodea et al., 2014). If the red nucleus is the main source of reelin for migrating mDA neurons, lack of red nucleus cells should cause malformation of the SNc. Interestingly, in Nkx6-1 KO mice the number of 
cells in the red nucleus is dramatically decreased at E12.5, and at E18.5 only $27 \%$ of these neurons remain (Prakash et al., 2009). Nkx6-1 is a transcription factor expressed in the BP by progenitors of red nucleus neurons, but not by $\mathrm{mDA}$ progenitors nor by mDA neurons. In Nkx6-1 KO mice, the dopamine system develops normally, suggesting that reelin expressed by the red nucleus may not be responsible for the correct tangential migration of SNc mDA neurons. Recently, reelin protein was detected in $\mathrm{mDA}$ neurons and in the surrounding area at P0, but not at earlier developmental stages (Sharaf et al., 2015). However, at P0 migration of $\mathrm{mDA}$ neurons is complete. In contrast, other work detects reelin in the extracellular space surrounding mDA neurons as early as E15.5. It is possible that other cells, such as embryonic striatal neurons which are reelin $^{+}$at E15.5, supply the midbrain with reelin through their axonal projections (Nishikawa et al., 2003). In this case, reelin may function as a chemoattractant for tangentially migrating $\mathrm{SNc} \mathrm{mDA}$ neurons, and lack of reelin could prevent SNc mDA neurons from orienting their processes in the correct direction.

In conclusion, experimental data show that reelin and its receptors are necessary for the correct tangential migration of a subset of $\mathrm{SNc} \mathrm{mDA}$ neurons. It remains to be determined whether reelin influences $\mathrm{SNc}$ mDA neuron movement directly by acting as an attractant guidance cue, or whether it is required for the correct development of the guidance scaffolds used by these neurons for migration.

\section{GROWTH AND GUIDANCE OF mDA AXONS}

\section{mDA Efferent and Afferent Connections}

The mouse mDA system contains around 30.000 neurons and despite its small size it is connected to many brain areas (Figures 1C, 4A). The majority of $\mathrm{mDA}$ axons is oriented rostroventrally in the diencephalon, and is tightly fasciculated into two ipsilateral axon bundles called the medial forebrain bundles (MFBs). The MFBs pass first through the ventral diencephalon and then toward the telencephalon. $\mathrm{mDA}$ axons projecting to the habenula do not elongate inside the MFB, but are instead oriented in a rostro-dorsal direction toward the lateral habenula, which resides in the diencephalon, using the fasciculus retroflexus as scaffold (Schmidt et al., 2014). Recent advances in brain tissue clearing and $3 \mathrm{D}$ reconstruction of axonal tracts has further unveiled the complex axon projections that derive from the mDA system (Belle et al., 2014; Renier et al., 2014) (Figure 4A). This approach holds great promise for analyzing the normal development of $\mathrm{mDA}$ axon connections and of defects in axon growth and guidance present in $\mathrm{KO}$ mouse models.

$\mathrm{SNc}$ and VTA mDA neurons target partly distinct areas in the forebrain. The SNc and the dorso-lateral VTA project to the dorsal striatum, forming the mesostriatal pathway. Medial $\mathrm{SNc} \mathrm{mDA}$ neurons innervate the dorso-medial striatum, while lateral $\mathrm{SNc} \mathrm{mDA}$ neurons project to the dorso-lateral striatum (Figure 1C) (Lerner et al., 2015). Within the striatum, each
SNc mDA neuron generates extensive axonal arborizations, establishing connections with on average 75.000 striatal neurons, positioned in both the striatal patch and matrix structure (Matsuda et al., 2009), which are two striatal compartments defined by different biochemical markers and different afferent and efferent connections (Gerfen, 1992).

VTA mDA neurons mainly project to the prefrontal cortex (PFC), the amygdala, and the ventral striatum, which is subdivided in the medial and lateral olfactory tubercle (mOT and IOT, respectively) and the nucleus accumbens (NAc - core, medial shell, lateral shell), forming the mesocorticolimbic pathway (Ikemoto, 2007; Lammel et al., 2008). VTA mDA neurons projecting to more medial regions of the ventral striatum are distributed medially within the VTA, whereas laterally positioned VTA mDA neurons establish connections with more lateral nuclei (Figure 1C) (Ikemoto, 2007; Lammel et al., 2008; Beier et al., 2015). In contrast to SNc mDA neurons, which have few collaterals outside the striatum, single VTA mDA neurons can have axon collaterals projecting to different brain areas. For example, a mDA neuron in the PBP can innervate both the cortex and the amygdala, while a neuron in the PN can establish connections with the amygdala, the NAccore, and the septum (Aransay et al., 2015). Other VTA mDA neurons, like those projecting to the lateral habenula, are more selective and do not have axon collaterals (Stamatakis et al., 2013).

SNc and VTA mDA neurons do not only differ with respect to the targets they innervate. Several studies in the past decade have also unveiled striking differences in the afferent inputs of $\mathrm{SNc}$ and VTA mDA neurons. For example, ventral striatum mainly innervates VTA mDA neurons, whereas dorsal striatum establishes connections with $\mathrm{SNc}$ mDA neurons. Interestingly, in the dorsal striatum, striatal neurons residing in striosomes establish connections preferentially with $\mathrm{SNc} \mathrm{mDA}$ neurons, while striatal neurons of the matrix show a preference for GABAergic neurons located in the SN reticulata (Gerfen et al., 1987; Fujiyama et al., 2011; Watabe-Uchida et al., 2012). Axonal projections from the NAc to the ventral midbrain mainly target VTA mDA neurons. Furthermore, SNc mDA neurons receive inputs from the somatosensory and motor cortex, subthalamic nucleus, superior colliculus, PAG, and DR (Watabe-Uchida et al., 2012). VTA mDA neurons receive glutamatergic inputs from the medial PFC, pedunculopontine tegmentum, laterodorsal tegmentum nucleus, lateral habenula, PAG, bed nucleus of the stria terminalis, and DR. VTA mDA neurons receive GABAergic inputs from the rostromedial mesopontine tegmental nucleus, PAG, lateral hypothalamus, ventral pallidum. There are also local glutamate and GABA synapses onto VTA mDA neurons arising from neurons within the VTA (recently reviewed in Morales and Margolis, 2017).

In conclusion, the efferent and afferent connections of SNc and VTA mDA neurons are strikingly distinct. In the following section, we discuss the different stages of $\mathrm{mDA}$ axon guidance and the molecules involved. We highlight differences between mDA axonal subsets, cell subtype-specific expression of axon guidance receptors, and the differential response to guidance cues. 
A

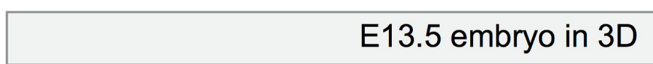

$A \stackrel{D}{\uparrow}$

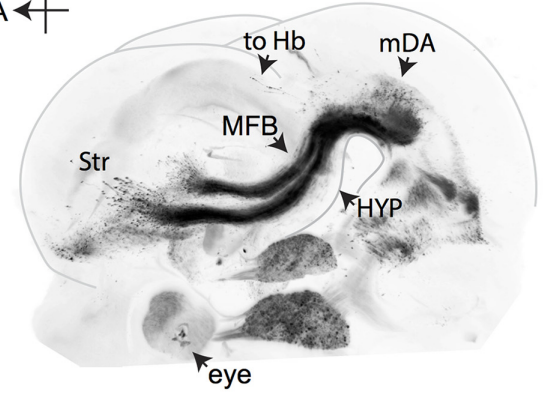

B 400 um

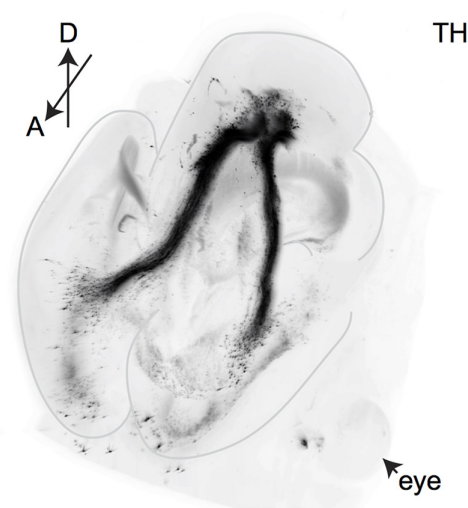

TH

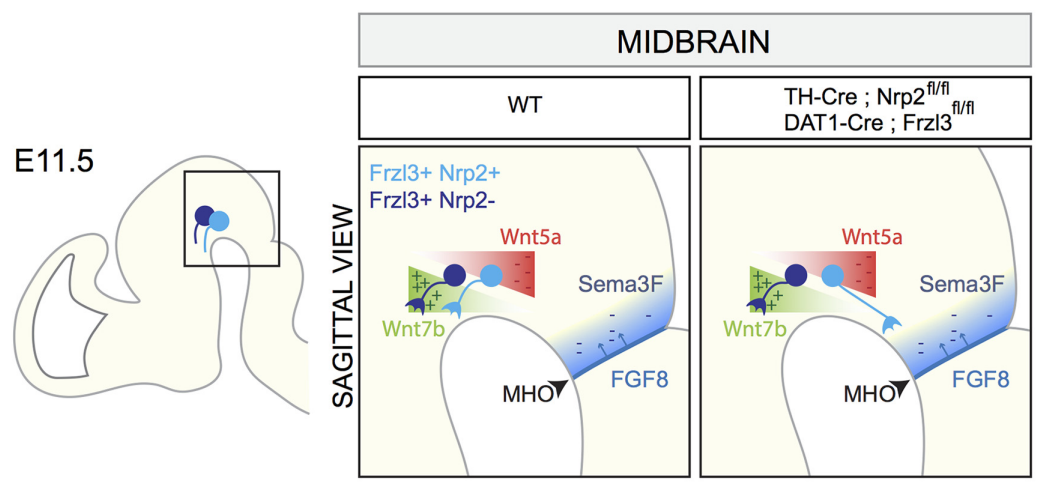

C

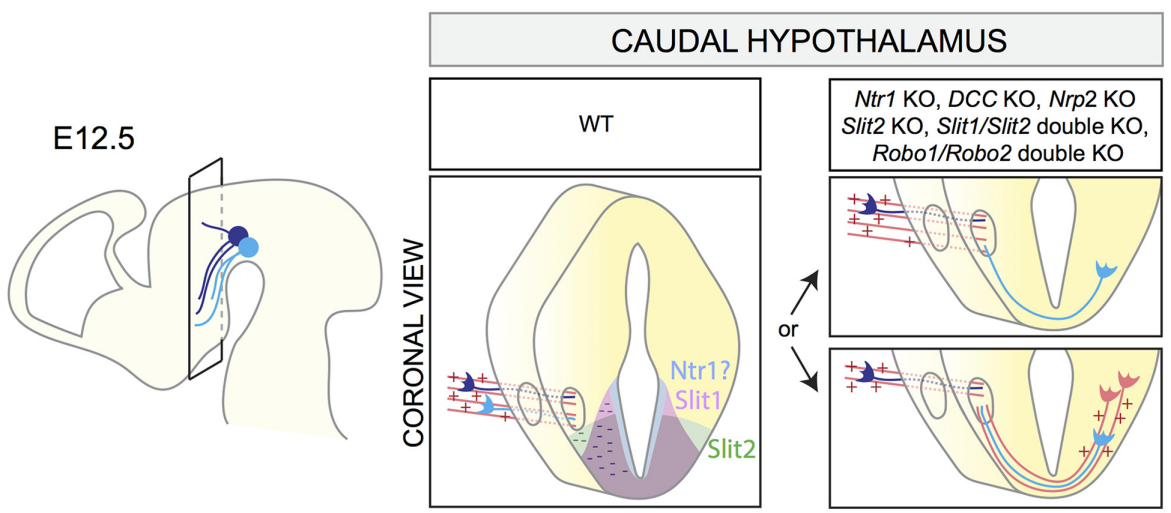

FIGURE 4 | 3D reconstruction of the E13.5 mDA system and schematic representations of different stages of mDA axon growth and guidance. (A) 3D reconstruction of a E13.5 mouse embryo head with a sagittal (left) and horizontal (right) view. The brain is immunostained for TH and cleared using the 3DISCO protocol (Brignani and Pasterkamp, unpublished data). 3D reconstruction shows mDA neurons positioned on top of the midbrain flexure. The majority of mDA axons elongates toward the forebrain forming the MFB. mDA axons projecting to the habenula (to Hb) do not grow in the MFB, but are instead oriented in a rostro-dorsal direction. At E13.5, the first mDA axons reach the striatum (Str). (B) The rostral orientation of mDA axons (represented in blue) in the midbrain is determined by the expression of gradients of guidance cues: Wnt7b acts as attractant (+) for growing mDA axons and shows an increasing caudo-rostral gradient, whereas Wnt5a functions as a repellent (-) and shows a rostro-caudal gradient. mDA axons express the receptor Fzd3 which mediates Wnt signaling. The conditional removal of Fzd3 from mDA neurons causes the misrouting of a subset of mDA axons toward the caudal midbrain. Moreover, in normal conditions, neurons of the MHO secrete FGF8 which in turn induces the expression of the repellent Sema3F (-). The Sema3F receptor Nrp2 is expressed by a subset of medial mDA neurons. The conditional removal of Nrp2 from mDA neurons causes the caudal misrouting of a subset of mDA axons. (C) The caudal hypothalamus expresses Netrin1, Slit1, and Slit2. mDA axons elongate longitudinally most likely following other pre-existing axons that function as scaffolds (red parallel lines). In Netrin1 KO, DCC KO, Nrp2 KO, Slit2 KO, Slit1/Slit2 double KO, and in Robo1/Robo2 double KO, a subset of mDA axons exits the MFB, turns ventrally, and crosses the midline growing to the contralateral side of the brain. This phenotype might be a result of lack of expression of repellent guidance cues (Netrin1, Slit1, and Slit2) or of the misrouting of pioneer axons which normally function as a scaffold for mDA axons. MFB, medial forebrain bundle; Str, striatum; HYP, hypothalamus; to Hb, indicates mDA fibers growing toward the habenula; $\mathrm{MHO}$, midbrain-hindbrain organizer. 


\section{Rostrally Oriented Axon Growth in the Midbrain}

The first $\mathrm{mDA}$ axons appear around E11 and their rostral orientation is determined by the expression of gradients of axon guidance cues along the A-P axis. An important signaling center involved in the generation of these molecular gradients is the midbrain-hindbrain organizer (MHO), which is positioned at the boundary between the caudal midbrain and the rostral hindbrain (Raible and Brand, 2004). Several secreted proteins are expressed by $\mathrm{MHO}$ cells, including members of the wingless (Wnt) and the fibroblast growth factor (FGF) families. The secretion of FGF8 by the MHO induces the expression of the axon repellent Semaphorin3F (Sema3F) (Yamauchi et al., 2009). At early developmental time points, Sema3F inhibits $\mathrm{mDA}$ axon outgrowth in vitro via its receptor Nrp2, which is expressed by a subset of medially positioned $\mathrm{mDA}$ neurons (HernándezMontiel et al., 2008; Kolk et al., 2009; Yamauchi et al., 2009). $\mathrm{Nrp2} \mathrm{KO}$ mice display mDA axons aberrantly growing caudally toward the MHO (Yamauchi et al., 2009). A similar phenotype is detected when Nrp2 is conditionally removed from mDA neurons (using TH-Cre mice) (Kolk et al., 2009). Together, these results indicate that Sema3F creates a non-permissive territory in the caudal midbrain for early $\mathrm{Nrp}^{+} \mathrm{mDA}$ axons (Figure 4B).

Wnts also contribute to the rostral orientation of mdDA axons. Wnt5a is expressed in a caudal-high-to-rostral-low gradient in the midbrain, whereas Wnt7b is expressed in an opposite molecular gradient. $\mathrm{mDA}$ neurons express the core planar cell polarity (PCP) components Frizzled3, Celsr3, and Vangl2, necessary for transducing Wnt-mediated signaling. In vitro, both SNc and VTA axons are repelled by Wnt5a (Fenstermaker et al., 2010; Blakely et al., 2013) and attracted by Wnt7b (Fenstermaker et al., 2010; Fernando et al., 2014). These effects are mediated by the receptor Frizzled3 (Fenstermaker et al., 2010). In Frizzled3, Celsr3, and Vangl2 KO mice, mDA axons lose their rostral orientation and display aberrant dorsal and caudal projections (Fenstermaker et al., 2010). Conditional deletion of Frizzled3 from mDA neurons (using DAT-Cre mice) causes similar defects in $\mathrm{mDA}$ axon orientation, with $\mathrm{mDA}$ axons forming a caudal tract that descends into the spinal cord (Hua et al., 2014). Abnormal, but transient, caudal mdDA axon projections are detected in Wnt5a KO mice (Fenstermaker et al., 2010). Together, these data show that Wnt-PCP signaling along the A-P axis of the midbrain is required for orienting $\mathrm{mDA}$ axons rostrally (Figure 4B).

\section{Axon Fasciculation in the MFB and Ipsilateral Projections}

In the ventral diencephalon, $\mathrm{mDA}$ axons form the MFB that traverses the diencephalon toward its targets in the telencephalon (Figure 4A). Axon guidance receptors and cues play a role in the fasciculation of axons within the MFBs and in preventing $\mathrm{mDA}$ axons from crossing the midline. During their growth in the diencephalon, $\mathrm{mDA}$ axons express several axon guidance receptors. Previous work has shown that from E12.5 onward, a subset of $\mathrm{mDA}$ axons positioned in the ventral MFB expresses Nrp2. The Nrp2 ligand Sema3F is expressed in several brain regions surrounding the trajectory of the MFB (Kolk et al., 2009; Yamauchi et al., 2009; Torigoe et al., 2013). In Nrp2 KO mice, the MFB is defasciculated. A similar phenotype is described in Sema3F KO mice and in conditional Nrp2 KO mice in which Nrp2 is removed from mDA neurons (Kolk et al., 2009) (Table 3). These observations together with data showing that Sema3F is a potent axon repellent for $\mathrm{Nrp}^{+} \mathrm{mDA}$ axons in vitro (Hernández-Montiel et al., 2008; Kolk et al., 2009; Yamauchi et al., 2009) indicate that Sema3F acts to fasciculate mDA axons en route to their distant targets.

The caudal hypothalamus is an important intermediate target for mDA axons. In KO mice lacking Netrin1, DCC, Slit2, Slit1 and Slit2, Robo1 and Robo2, or Nrp2, a subset of mDA axons leaves the MFB at the level of the caudal hypothalamus and turns ventrally to form an abnormal axon bundle that crosses the ventral midline (Bagri et al., 2002; Xu et al., 2010; Dugan et al., 2011; Torigoe et al., 2013; Li et al., 2014) (Figure 4C and Table 3). In Nrp2 $\mathrm{KO}$ mice, the use of a $\beta$-galactosidase reporter that is present downstream of the Nrp2 promoter shows that this promoter is active in the ventral part of the MFB and in the aberrantly projecting axons. Since $\mathrm{Nrp}^{+} \mathrm{mDA}$ neurons are normally positioned medially in the $\mathrm{mDA}$ system (Kolk et al., 2009; Yamauchi et al., 2009; Torigoe et al., 2013), these results suggest that the abnormal ventral axon projections in Nrp2 $\mathrm{KO}$ mice originate from a subset of $\mathrm{mDA}$ neurons, most probably located in the VTA. It remains to be determined whether the aberrant ventral $\mathrm{mDA}$ axon bundles detected in the other $\mathrm{KO}$ mice also derive from specific $\mathrm{mDA}$ neuron subsets. Furthermore, it is unclear whether in these $\mathrm{KO}$ mice the abnormal projections form as a result of a lack of expression of axon repellent cues in ventral structures, e.g., such as Slit1, Slit2, and Netrin1, or of defects in other axon bundles that normally function as scaffolds for $\mathrm{mDA}$ axons. $\mathrm{mDA}$ axons are not the first axons to extend along the A-P axis of the developing brain. For example, at E13 mDA axons in the MFB interact with GAD65 ${ }^{+}$ axons extending along the A-P axis toward the striatum. These axons might be descending fibers coming from the telencephalon and/or from the mammillary bodies of the caudal hypothalamus forming the mammillo-tegmental tract. The in vivo ablation of GAD $65^{+}$axons induces many $\mathrm{mDA}$ axons to turn ventrally into the hypothalamic region (Garcia-Peña et al., 2014). These data strongly suggest that (at least) a subset of $\mathrm{mDA}$ axons needs other pre-existing longitudinal axons as scaffolds for guidance to rostral targets.

\section{Innervation of the Striatum}

The striatum is a major target of $\mathrm{mDA}$ axons. Striatal innervation by $\mathrm{mDA}$ axons starts around E13.5 (Figure $\mathbf{4 A}$ ). In vitro both late embryonic and postnatal, but not early embryonic, striatal explants attract mDA axons (Gates et al., 2004). Following their entry into the striatum, $\mathrm{mDA}$ axons arborize extensively. Co-culturing mDA neurons with striatal neurons enhances axonal branching. The same effect is observed when culturing $\mathrm{mDA}$ neurons with medium conditioned by striatal neurons, indicating that secreted cues are expressed by the striatum to 
TABLE 3 | Canonical axon guidance genes involved in mDA pathway development.

\begin{tabular}{|c|c|c|c|c|c|}
\hline $\begin{array}{l}\text { Axon guidance } \\
\text { gene(s) }\end{array}$ & Species & In vivo observations & In vitro observations & Expression data & Reference \\
\hline $\begin{array}{l}\text { EphrinA/EphA } \\
\text { signaling }\end{array}$ & Mice & $\begin{array}{l}\text { Transgenic mice expressing } \\
\text { EphA5ecto-Fc show } \\
40-50 \% \text { less mDA neurons } \\
\text { innervating the striatum. }\end{array}$ & & & Sieber et al., 2004 \\
\hline EphrinA5 & Mice ${ }^{a, b}$, Rats $^{b}$ & $\begin{array}{l}\text { No developmental defects } \\
\text { in mDA system }{ }^{\mathrm{a}} ; 10 \% \\
\text { reduction in the number of } \\
\text { mDA neurons innervating } \\
\text { the striatum }{ }^{\mathrm{b}} \text {. }\end{array}$ & $\begin{array}{l}\text { mDA axon repellenta; }{ }^{\mathrm{a} D A} \\
\text { axon growth promotion via } \\
\text { EphA5 }{ }^{\mathrm{b}} \text {. }\end{array}$ & $\begin{array}{l}\text { mRNA expression in the } \\
\text { ventral midbrain dorsally to } \\
\mathrm{TH}^{+} \text {neurons, in the } \\
\text { thalamus, and in the } \\
\text { striatum }^{\mathrm{a}} \text {; mRNA } \\
\text { expression in the } \\
\text { dorso-lateral striatum and } \\
\mathrm{NAc-shell} \text {. }\end{array}$ & $\begin{array}{l}\text { aDeschamps et al., } 2010 \\
\text { b'Cooper et al., } 2009\end{array}$ \\
\hline EphA5 & Mice & $\begin{array}{l}14 \% \text { reduction in the } \\
\text { number of mDA neurons } \\
\text { innervating the striatum. }\end{array}$ & $\begin{array}{l}\text { mDA axon growth } \\
\text { promotion via EphrinA5. }\end{array}$ & $\begin{array}{l}\text { Promoter activity in } \\
\text { developing VTA and SNc } \\
\text { mDA neurons. }\end{array}$ & Cooper et al., 2009 \\
\hline EphB1 & Mice & $\begin{array}{l}\text { No structural defect in the } \\
\text { mDA system }{ }^{b} \text {. }\end{array}$ & & $\begin{array}{l}\text { Higher mRNA levels in SNc } \\
\text { than VTA mDA neurons } \\
\text { from } \mathrm{E} 18 \text { to } \mathrm{P}^{\mathrm{a}} \text {. No } \\
\text { promoter activity in mDA } \\
\text { neurons, but detected in } \\
\text { neurons of the } \mathrm{SN} \\
\text { reticulata }^{\mathrm{b}} \text {. }\end{array}$ & $\begin{array}{l}\text { aYue et al., } 1999 \\
\text { brichards et al., } 2007\end{array}$ \\
\hline$D C C$ & Mice $^{a}$, Rats $^{b}$ & $\begin{array}{l}\text { Aberrant migration of a } \\
\text { subset of mDA neurons; } \\
\text { abnormal mDA innervation } \\
\text { of the ventral striatum; } \\
\text { reduced mDA innervation of } \\
\text { the cortex, and a subset of } \\
\text { mDA axons crosses the } \\
\text { midline at the level of the } \\
\text { caudal hypothalamusa. }\end{array}$ & $\begin{array}{l}\text { Function blocking anti-DCC } \\
\text { antibody blocks mDA axon } \\
\text { elongation and branching } \\
\text { induced by Netrin } 1^{\mathrm{a}} \text {. }\end{array}$ & $\begin{array}{l}\text { Protein expression in both } \\
\text { SNc and VTA mDA neurons } \\
\text { from } \mathrm{E} 14 \text { to } \mathrm{E} 18^{\mathrm{a}} \text {. In } \\
\text { dissociated } \mathrm{E} 14 \mathrm{mDA} \\
\text { neurons, protein expression } \\
\text { more abundant in SNc } \\
\text { mDA neurons than VTA } \\
\text { mDA neurons }{ }^{\mathrm{b}} \text {. }\end{array}$ & $\begin{array}{l}\text { aXu et al., } 2010 \\
\text { bLin et al., } 2005\end{array}$ \\
\hline Robo1 & Rats $^{a}$, Mice $^{b}$ & $\begin{array}{l}\text { KO mice show a wider } \\
\text { MFB, with a subset of mDA } \\
\text { axons deviating both } \\
\text { ventrally and dorsally }{ }^{\mathrm{b}} \text {. In } \\
\text { Robo } 1 / \text { Robo2 double KO } \\
\text { mice a subset of mDA } \\
\text { axons crosses the midline } \\
\text { at the level of the caudal } \\
\text { hypothalamus, mDA axons } \\
\text { leave the MFB to grow } \\
\text { dorsally }{ }^{\mathrm{b}} \text {. }\end{array}$ & & $\begin{array}{l}\text { Expression in dissociated } \\
\text { E14 mDA neurons }{ }^{\text {a }} \text {. } \\
\text { Expression in some mDA } \\
\text { neurons and by longitudinal } \\
\text { fibers in close association } \\
\text { with mDA axons of the } \\
\text { MFB }^{\mathrm{b}} \text {. }\end{array}$ & $\begin{array}{l}\text { aLin et al., } 2005 \\
\text { bDugan et al., } 2011\end{array}$ \\
\hline
\end{tabular}


TABLE 3 | Continued

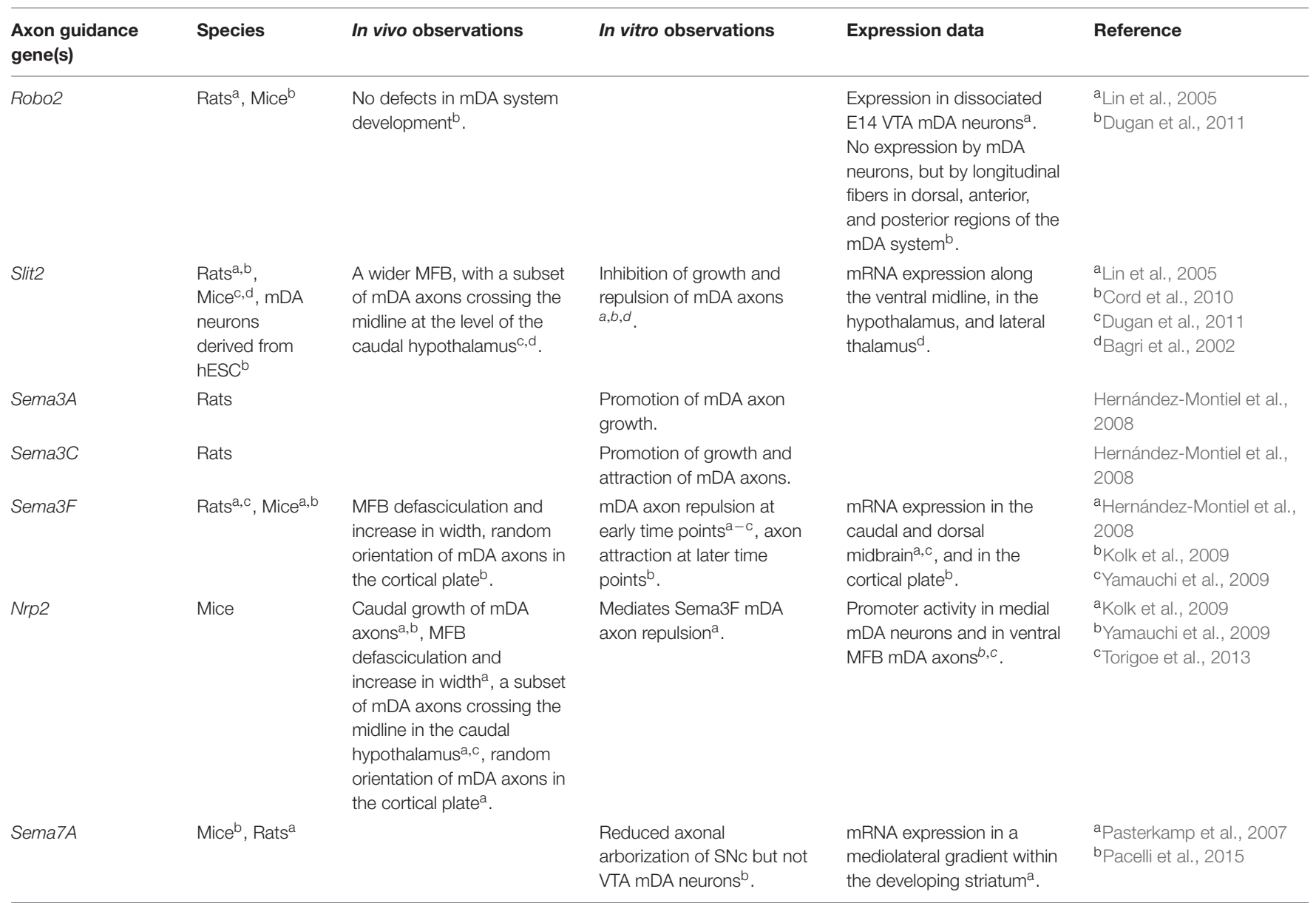

Overview of in vivo and in vitro experiments reported in literature linking canonical axon guidance genes to different aspects of mDA pathway development. Expression data as reported in literature are shown.

promote mDA branching (Manier et al., 1997). Several axon guidance cues are expressed by the striatum that may play a role in the innervation of $\mathrm{mDA}$ axons and the subsequent branching of these axons (Table 3 and reviewed in Van den Heuvel and Pasterkamp, 2008; Prestoz et al., 2012). Netrin1 is an interesting candidate as it induces $\mathrm{mDA}$ axon attraction (Li et al., 2014), elongation, and branching (Xu et al., 2010) via DCC. Analyses of the effects of Netrin1 on SNc and VTA explants show that effects of mDA axon attraction and elongation are induced at lower Netrin1 concentrations in SNc explants as compared to VTA explants. Interestingly, SNc $\mathrm{mDA}$ axons do not respond to high Netrin1 concentrations (Li et al., 2014). In vivo, Netrin1 expression is high in the ventro-lateral and low in the dorso-medial striatum. In Netrin1 $\mathrm{KO}$ mice, $\mathrm{SNc}$ axons fail to innervate the dorsal striatum and accumulate in the ventral striatum ( $\mathrm{Li}$ et al., 2014). On basis of these data it was proposed that SNc axons innervate the dorsal striatum attracted by low levels of Netrin1 expression, whereas VTA axons are directed to the ventral striatum attracted by higher Netrin 1 concentration. The molecular basis for this differential sensitivity to Netrin1 of SNc and VTA $\mathrm{mDA}$ axons remains unknown but could include differential expression of axon guidance (co-)receptors or intracellular signaling cues.

The striatum is mainly composed of medium spiny neurons (MSNs), and displays a unique mosaic organization composed of two neuroanatomically and neurochemically distinct compartments called the matrix and patches (or striosomes) (Gerfen, 1992). Patch neurons are generated first and migrate from the lateral ganglionic eminence to the striatal mantle from E11-E12, followed by matrix neurons that start striatal mantle invasion at E13 (van der Kooy and Fishell, 1987; Mason et al., 2005). The two populations are initially intermingled in the striatal mantle, then segregate to form the matrix/patch mosaic at E18. At this age, both patch and matrix MSNs extend their dendrites almost exclusively within their respective compartments (Kawaguchi et al., 1989). The first mDA axons arrive in the developing striatum around E13, and therefore most likely receive guidance from patch MSNs. At this age, $\mathrm{mDA}$ innervation is sparse and scattered. From E18 onward, the entire striatum is innervated, but $\mathrm{TH}^{+}$innervation is denser in striatal patches as compared to the matrix. These areas of dense $\mathrm{TH}^{+}$innervation are called "dopamine islands," and are detectable until P15, after which striatal innervation of $\mathrm{mDA}$ 
axons becomes more homogeneous (Edley and Herkenham, 1984). Initially, it was thought that in adult rat brain most mDA neurons of the ventral SNc were arborizing in patches, while dorsal SNc mDA axons were innervating the matrix compartment (Prensa and Parent, 2001). However, more recently it has been demonstrated that in adult mice both ventral and dorsal SNc mDA neurons innervate both striatal compartments (Matsuda et al., 2009).

Depletion of mDA neurons at early developmental timepoints does not cause changes in striatal patch/matrix organization. This indicates that aggregation of patch MSNs is independent from mDA innervation (Snyder-Keller, 1991). In contrast, the formation of 'dopamine islands' strictly relies on correct striatal development. In Ctip2 KO mice and Notch1 KO mice, where patch/matrix organization is lost and patches are not formed, dopaminergic innervation is correct at E15 (before aggregation of patch MSNs occurs), but disorganized and diffuse at P0 without discernable 'dopamine islands' (Mason et al., 2005; Arlotta et al., 2008). These results suggest that patch MSNs express molecular cues that induce the aggregation of a subset of $\mathrm{mDA}$ axons to form 'dopamine islands.' Interesting candidates for such a role are Ephs and ephrins. For example, the EphA4 receptor and its ligand ephrinA5 are expressed by matrix and patch MSNs, respectively, and are required for the correct development of striatal compartments (Passante et al., 2008). Other Ephs are also enriched in striatal patches, e.g., EphA7 and EphA8 (Allen Brain Atlas). The precise function of 'dopamine islands' during development remains to be determined, whether their transient appearance is necessary for the development of the postnatal brain, and which guidance molecules induce $\mathrm{mDA}$ axons to aggregate in the patch compartment.

\section{Innervation of the Medial Prefrontal Cortex}

VTA mDA axons follow two trajectories to reach the mPFC: (1) a subset of axons exits from the MFB at the point where most mdDA axons enter the striatum and then extends rostrally to move into the PFC just caudal of the olfactory bulb; and (2) another subset of VTA mDA extends through the striatum, crosses the external capsule and innervates the mPFC. Within the $\mathrm{mPFC}$, the first $\mathrm{mDA}$ axons are detected in the subplate (SP) and the marginal zone (MZ) around E15. At E16.5, the innervation of these regions increases, while the cortical plate (CP) remains devoid of $\mathrm{mDA}$ axons. After a waiting period of 2 days, $\mathrm{mDA}$ axons invade the $\mathrm{CP}$ from the SP, following a radial path (Kolk et al., 2009). Such a waiting period for mesocortical mDA projections is observed also in human PFC (Verney, 1999).

In vitro $\mathrm{mPFC}$ explants release diffusible molecules that induce mDA VTA subset-specific axon outgrowth. From E14 onward, rostral VTA explants are attracted by $\mathrm{mPFC}$, whereas caudal VTA explants are repelled (Kolk et al., 2009). This observation strongly suggests that rostral VTA mDA neurons, but not caudal VTA mDA neurons, constitute the VTA cell subtype that establish connections with the mPFC. Sema3F is expressed in the $\mathrm{CP}$ and exerts an interesting bifunctional guidance effect on rostral VTA explants: at E12.5, Sema3F is a strong repellent, while at E14.5 becomes an attractant. Both effects are mediated by the Nrp2 receptor. Despite the presence of several mDA axonal defects along the trajectory of $\mathrm{mDA}$ axons (caudal growth into the midbrain, MFB defasciculation, and hypothalamic innervation), many $\mathrm{mDA}$ axons reach the $\mathrm{mPFC}$. Here, chemoattraction mediated by Sema3F and Nrp2 is required to orient mDA axons projections in the CP (Kolk et al., 2009). The bifunctional effect of Sema3F is an important molecular mechanism that allows one molecule to exert distinct effects in different spatio-temporal conditions. As we discussed previously, Sema3F acts first as a repellent for $\mathrm{mDA}$ axons in the midbrain, directing them toward the diencephalon. Then, when mDA axons approach the mPFC, Sema3F becomes an attractant to promote the correct innervation of the CP. Although, it has been demonstrated that both the attractant and repellent effects of Sema3F are mediated by Nrp2, further work is needed to dissect how a single receptor can transduce two opposite biological effects.

\section{Innervation of the Habenula}

The habenula is positioned in the dorso-medial diencephalon and is composed of two main subdomains: the lateral ( $\mathrm{LHb}$ ) and the medial habenula $(\mathrm{MHb})$. The $\mathrm{MHb}$ projects primarily to the interpeduncular nucleus, whereas the $\mathrm{LHb}$ innervates monoaminergic nuclei, including the mDA system (Hikosaka et al., 2008). Efferent habenular axons fasciculate together to form the fasciculus retroflexus (FR), which has an outer sheath of LHb axons surrounding a core of $\mathrm{MHb}$ axons (Bianco and Wilson, 2009). VTA mDA axons projecting to the LHb are confined to the sheath domain of the FR (Schmidt et al., 2014; Figure 5).

VTA mDA axons start growing toward the habenula around E12.5 and arrive at this structure by E13.5. At E16.5, mDA axons are detectable in the LHb, but not in the MHb. The first phase of $\mathrm{mDA}$ axon navigation relies on the FR that is used as a scaffold by $\mathrm{mDA}$ axons. In vivo genetic ablation of the habenula and blockage of habenular axons in vitro prevent mDA axon growth toward the habenula. The physical interaction between $\mathrm{mDA}$ axons and axons of the sheath is required for the correct development of the system, and limbic-system associated membrane protein (LAMP) is an important mediator of this process. Reduced expression or lack of LAMP from LHb-sheath axons, or blockage of LAMP function by anti-LAMP antibodies induces the detachment of $\mathrm{TH}^{+}$axons from the FR, impeding their growth to the LHb (Schmidt et al., 2014). Once mDA axons arrive at the habenula, the innervation of the LHb is mediated by Netrin1/DCC signaling. Netrin 1 is expressed by the LHb, but not the $\mathrm{MHb}$, and is a potent attractant for the $\mathrm{DCC}^{+}$ $\mathrm{mDA}$ axons that are approaching the lateral nucleus. In both Netrin 1 and DCC $\mathrm{KO}$ mice, $\mathrm{mDA}$ axons no longer innervate the LHb, but instead stall at its ventral border (Schmidt et al., 2014). In conclusion, these data show that the LHb determines its own dopaminergic afferents by projecting axons toward the VTA. mDA axons are collected and guided by habenular axons of FR-sheath, relying on a mechanism of reciprocal axonaxon interactions. This process cooperates with a mechanism of LHb-specific chemoattraction, which controls the target entry of the LHb (Figure 5). 


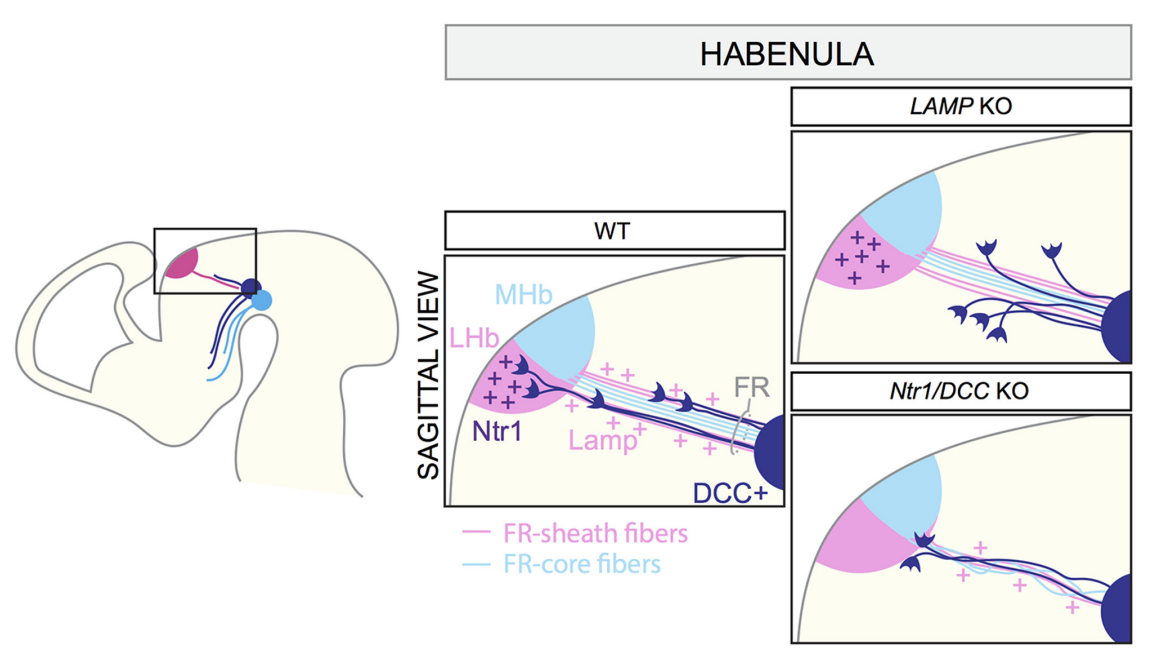

FIGURE 5 | Axon-axon interactions during the formation of dopaminergic input of the habenula. MHb and LHb projections grow toward the ventral midbrain forming the fasciculus retroflexus (FR). LHb fibers form the FR-sheath, while MHb axons are confined inside forming the FR-core. Habenular axons of the sheath express the adhesion molecule LAMP, which allows the physical interaction of mDA axons and FR-sheath fibers important for mDA axon guidance. Once mDA axons arrive at the edge of the LHb nucleus, Netrin1 expressed by the LHb neurons attracts mDA axons. DCC expressed by mDA axons mediates Netrin1 signaling. In LAMP KO mice, mDA axons are detached from the FR and, as a consequence, they cannot reach the LHb nucleus. In both Netrin 1 and DCC KO brains, mDA axons no longer innervate the LHb, but instead stall at its ventral border. LHb, lateral habenula; MHb, medial habenula; FR, fasciculus retroflexus.

\section{Subset-Specific Transcription Factors Control Axon Guidance Gene Expression}

As described in this section, during brain development, the expression of different axon guidance receptors allows subsets of $\mathrm{mDA}$ axons to respond to specific environmental cues that steer them to the correct target. The expression of different guidance receptors derives from the activation of specific developmental programs that differ between mDA neuron subsets. Many studies have analyzed which transcription factors specifically characterize SNc and VTA mDA neurons, but only a few studies have focused on the expression of axon guidance receptors induced by subset-specific transcription factors. Interesting examples are the transcription factors Otx2 and Sox6, expressed by VTA and SNc mDA neurons, respectively (Panman et al., 2014). In vitro overexpression of Otx 2 in $\mathrm{mDA}$ neurons increases the expression of the guidance receptors $\mathrm{Nrp} 1$ and $\mathrm{Nrp} 2$, whereas PlxnC1 and EphB3 levels are unaffected. Downregulation of Otx2 causes the opposite effect. This indicates that transcription of $N r p 1$ and $N r p 2$ in VTA mDA neurons relies on the subset-specific transcription factor Otx2 (Chung et al., 2010). As we discussed, Nrp2 is an important receptor required during several stages of VTA mDA axon navigation (e.g., $\mathrm{mDA}$ axon orientation in the midbrain, fasciculation of the MBF, and MPFC innervation). Sox6 is necessary for EphA5 expression in SNc mDA neurons (Panman et al., 2014). In Sox6 KO mice, SNc mDA neurons lack EphA5 expression (Panman et al., 2014), which is required for the correct innervation of the striatum (Cooper et al., 2009). However, in contrast to the subset-specific expression of Nrp2, the EphA5 promoter is active in both SNc and VTA mDA neurons (Cooper et al., 2009). This suggests then that the expression of EphA5 in VTA mDA neurons is regulated by another transcription factor. Future studies are needed to further unravel the transcription factor networks that control subset-specific axon guidance cue expression.

\section{FUTURE DIRECTIONS}

Because of their diverse functional roles and their implication in disease, $\mathrm{mDA}$ neurons have been studied extensively. Many studies have recently focused on dissecting the molecular programs that dictate the formation of mDA connectivity. This has led to the identification of an increasing number of molecular cues that control the migration of embryonic mDA neurons or the guidance of their axons. Furthermore, approaches such as single cell-omics have begun to provide insight into the different neuronal subsets that comprise the mDA system. More studies focused on further understanding the heterogeneity of $\mathrm{mDA}$ neurons are needed for several reasons: (1) SNc mDA neurons are more prone to degeneration in Parkinson's disease than VTA neurons (Albin et al., 1989). The identification of molecular profiles that correlate with different $\mathrm{mDA}$ neurons subsets may increase our understanding of why certain neurons are more vulnerable to degenerate than others. (2) Understanding the molecular features of different $\mathrm{mDA}$ subsets may improve the generation and the characterization of iPSC-derived $\mathrm{mDA}$ neurons subsets. This will help to obtain better in vitro models of human $\mathrm{mDA}$ cell-types and more specific $\mathrm{mDA}$ neurons to transplant into Parkinson's disease patients. (3) New genetic markers selective for $\mathrm{mDA}$ subsets can be used to generate Cre or Flp mouse lines to target mDA cell types. These new mouse lines would allow the expression of fluorescent reporter proteins for the visualization of $\mathrm{mDA}$ neuronal subsets, to conditionally knock-out genes and study their functions, and 
to perform optogenetic analyses on molecularly homogeneous $\mathrm{mDA}$ neurons. In particular, in vivo florescent labeling of $\mathrm{mDA}$ neuron subsets will allow researchers to study migration and axon guidance of each neuronal subset individually, to isolate mDA subsets, and to determine their precise molecular profile. In addition, this approach will allow the analysis of structural alterations of $\mathrm{mDA}$ neuron subsets in mice lacking axon guidance genes involved in $\mathrm{mDA}$ system wiring, to specifically link the function of axon guidance genes to $\mathrm{mDA}$ neuronal cell types.

Despite recent progress, many questions remain. For example, in the adult brain, $\mathrm{mDA}$ neurons receive afferents from many different brain areas, but the developmental programs involved in establishing $\mathrm{mDA}$ afferent connections remain largely unidentified. Furthermore, while many cues are now known to affect mDA axons, the structure and development of mDA dendrites remains largely unexplored. Technological advances such as light-sheet microscopy and single-cell omics approaches will help to provide insight into these and other questions.

A better understanding of $\mathrm{mDA}$ system development is also essential from a clinical perspective. $\mathrm{mDA}$ neurons of the VTA have been implicated in disorders such as drug addiction, depression, and schizophrenia (reviewed in Morales and Pickel, 2012; Walsh and Han, 2014), and evidence indicates that developmental and/or adult structural changes of neuronal networks may in part underline the pathogenesis of these disorders (Robinson and Kolb, 2004). In particular for drug addiction-behavior, it has been shown that the expression of axon guidance genes changes in the mDA system after a long administration of drugs, and drug-induced behaviors can be altered upon genetic manipulation of axon guidance genes (Sieber et al., 2004; Flores et al., 2005; Auger et al., 2013; Pokinko et al., 2015). Furthermore, genome-wide association studies and gene expression profiling have linked axon guidance proteins

\section{REFERENCES}

Afonso-Oramas, D., Cruz-Muros, I., Álvarez de la Rosa, D., Abreu, P., Giráldez, T., et al. (2009). Dopamine transporter glycosylation correlates with the vulnerability of midbrain dopaminergic cells in parkinson's disease. Neurobiol. Dis. 36, 494-508. doi: 10.1016/j.nbd.2009.09.002

Albin, R. L., Young, A. B., and Penney, J. B. (1989). The functional anatomy of basal ganglia disorders. Trends Neurosci. 12, 366-75. doi: 10.1016/0166-2236(89) 90074-X

Aransay, A., Rodríguez-López, C., García-Amado, M., Clascá, F., and Prensa, L. (2015). Long-range projection neurons of the mouse ventral tegmental area: a single-cell axon tracing analysis. Front. Neuroanat. 9:59. doi: 10.3389/fnana. 2015.00059

Arlotta, P., Molyneaux, B. J., Jabaudon, D., Yoshida, Y., and Macklis, J. D. (2008). Ctip2 controls the differentiation of medium spiny neurons and the establishment of the cellular architecture of the striatum. J. Neurosci. 28, 622-632. doi: 10.1523/JNEUROSCI.2986-07.2008

Auger, M. L., Schmidt, E. R. E., Manitt, C., Dal-Bo, G., Pasterkamp, R. J., and Flores, C. (2013). unc5c haploinsufficient phenotype: striking similarities with the dcc haploinsufficiency model. Eur. J. Neurosci. 38, 2853-2863. doi: 10.1111/ ejn. 12270

Bäckman, C. M., Malik, N., Zhang, Y. J., Shan, L., Grinberg, A., Hoffer, B. J., et al. (2006). Characterization of a mouse strain expressing cre recombinase from the 3' untranslated region of the dopamine transporter locus. Genesis 44, 383-390. doi: $10.1002 /$ dvg. 20228 to Parkinson's disease (reviewed in Van Battum et al., 2015). Due to their roles in $\mathrm{mDA}$ system development, changes in the expression or function of axon guidance genes may lead to defects in the formation or maintenance of $\mathrm{mDA}$ neuron connectivity and function. Although axon guidance events are crucial for the correct development of mDA nigrostriatal and mesocorticolimbic pathways, their precise role during the pathogenesis of mDA system-related diseases has not been established. Further studies on the role of axon guidance molecules during the development and plasticity of $\mathrm{mDA}$ networks are required to better understand their potential contribution to diseases. Understanding how the dopamine system develops will also aid the development of more effective of cell-replacement strategies in Parkinson's disease patients. The molecular ingredients required to build a functional mesostriatal pathway could be applied to improve the integration of transplanted mDA neurons into the degenerating dopamine system.

\section{AUTHOR CONTRIBUTIONS}

SB designed Figures. SB and RJP wrote the manuscript.

\section{FUNDING}

Work on axon guidance and the developing dopamine system is financially supported by the Netherlands Organization for Scientific Research (ALW-VICI), the People Program (Marie Curie Actions) of the European Union's Seventh Framework Program (FP7) 2007-2013 under REA grant agreement number 289581 (NPlast), the UU Strategic Theme "Dynamics of Youth", and Stichting ParkinsonFonds.

Bagri, A., Marın, O., Plump, A. S., Mak, J., Pleasure, S. J., Rubenstein, J. L. R., et al. (2002). Slit proteins prevent midline crossing and determine the dorsoventral position of major axonal pathways in the mammalian forebrain. Neuron 33, 233-248. doi: 10.1016/S0896-6273(02)00561-5

Bayer, S. A., Wills, K. V., Triarhou, L. C., and Ghetti, B. (1995). Time of neuron origin and gradients of neurogenesis in midbrain dopaminergic neurons in the mouse. Exp. Brain Res. 105, 191-199. doi: 10.1007/BF0024 0955

Beier, K. T., Steinberg, E. E., DeLoach, K. E., Xie, S., Miyamichi, K., Schwarz, L., et al. (2015). Circuit architecture of VTA dopamine neurons revealed by systematic input-output mapping. Cell 162, 622-634. doi: 10.1016/j.cell.2015. 07.015

Belle, M., Godefroy, D., Dominici, C., Heitz-Marchaland, C., Zelina, P., Hellal, F., et al. (2014). A simple method for 3D analysis of immunolabeled axonal tracts in a transparent nervous system. Cell Rep. 9, 1191-1201. doi: 10.1016/j.celrep. 2014.10.037

Bianco, I. H., and Wilson, S. W. (2009). The habenular nuclei: a conserved asymmetric relay station in the vertebrate brain. Philos. Trans. R. Soc. B Biol. Sci. 364, 1005-1020. doi: 10.1098/rstb.2008.0213

Blaess, S., Bodea, G. O., Kabanova, A., Chanet, S., Mugniery, E., Derouiche, A., et al. (2011). Temporal-spatial changes in sonic hedgehog expression and signaling reveal different potentials of ventral mesencephalic progenitors to populate distinct ventral midbrain nuclei. Neural Dev. 6:29. doi: 10.1186/1749-8104-6-29

Blakely, B. D., Bye, C. R., Fernando, C. V., Prasad, A. A., Pasterkamp, R. J., Macheda, M. L., et al. (2013). Ryk, a receptor regulating wnt5a-mediated 
neurogenesis and axon morphogenesis of ventral midbrain dopaminergic neurons. Stem Cells Dev. 22, 2132-2144. doi: 10.1089/scd.2013.0066

Bodea, G. O., Spille, J.-H., Abe, P., Andersson, A. S., Acker-Palmer, A., Stumm, R., et al. (2014). Reelin and CXCL12 regulate distinct migratory behaviors during the development of the dopaminergic system. Development 141, 661-673. doi: 10.1242/dev.099937

Bye, C. R., Thompson, L. H., and Parish, C. L. (2012). Birth dating of midbrain dopamine neurons identifies A9 enriched tissue for transplantation into parkinsonian mice. Exp. Neurol. 236, 58-68. doi: 10.1016/j.expneurol.2012. 04.002

Chaudhury, D., Walsh, J. J., Friedman, A. K., Juarez, B., Ku, S. M., Koo, J. W., et al. (2012). Rapid regulation of depression-related behaviours by control of midbrain dopamine neurons. Nature 493, 532-536. doi: 10.1038/nature11713

Chung, C. Y., Licznerski, P., Alavian, K. N., Simeone, A., Lin, Z., Martin, E., et al. (2010). The transcription factor orthodenticle homeobox 2 influences axonal projections and vulnerability of midbrain dopaminergic neurons. Brain? J. Neurol. 133(Pt 7), 2022-2031. doi: 10.1093/brain/awq142

Cooper, M. A., Kobayashi, K., and Zhou, R. (2009). Ephrin-A5 regulates the formation of the ascending midbrain dopaminergic pathways. Dev. Neurobiol. 69, 36-46. doi: 10.1002/dneu.20685

Cord, B. J., Li, J., Works, M., McConnell, S. K., Palmer, T., and Hynes, M. A. (2010). Characterization of axon guidance cue sensitivity of human embryonic stem cell-derived dopaminergic neurons. Mol. Cell. Neurosci. 45, 324-334. doi: 10.1016/j.mcn.2010.07.004

D'Arcangelo, G. (2014). Reelin in the years: controlling neuronal migration and maturation in the mammalian brain. Adv. Neurosci. 2014, 1-19. doi: 10.1155/ 2014/597395

Deschamps, C., Morel, M., Janet, T., Page, G., Jaber, M., Gaillard, A., et al. (2010). EphrinA5 protein distribution in the developing mouse brain. BMC Neurosci. 11:105. doi: 10.1186/1471-2202-11-105

Di Giovannantonio, L. G., Di Salvio, M., Acampora, D., Prakash, N., Wurst, W., and Simeone, A. (2013). Otx2 selectively controls the neurogenesis of specific neuronal subtypes of the ventral tegmental area and compensates En1dependent neuronal loss and MPTP vulnerability. Dev. Biol. 373, 176-183. doi: 10.1016/j.ydbio.2012.10.022

Di Salvio, M., Di Giovannantonio, L. G., Acampora, D., Prosperi, R., Omodei, D., Prakash, N., et al. (2010). Otx2 controls neuron subtype identity in ventral tegmental area and antagonizes vulnerability to MPTP. Nat. Neurosci. 13, 1481-1488. doi: 10.1038/nn.2661

Dugan, J. P., Stratton, A., Riley, H. P., Farmer, W. T., and Mastick, G. S. (2011). Midbrain dopaminergic axons are guided longitudinally through the diencephalon by slit/robo signals. Mol. Cell. Neurosci. 46, 347-356. doi: 10.1016/ j.mcn.2010.11.003

Edley, S. M., and Herkenham, M. (1984). Comparative development of striatal opiate receptors and dopamine revealed by autoradiography and histofluorescence. Brain Res. 305, 27-42. doi: 10.1016/0006-8993(84)91116-8

Ekstrand, M. I., Nectow, A. R., Knight, Z. A., Latcha, K. N., Pomeranz, L. E., and Friedman, J. M. (2014). Molecular profiling of neurons based on connectivity. Cell 157, 1230-1242. doi: 10.1016/j.cell.2014.03.059

Faraone, S. V., Perlis, R. H., Doyle, A. E., Smoller, J. W., Goralnick, J. J., Holmgren, M. A., et al. (2005). Molecular genetics of attention-deficit/hyperactivity disorder. Biol. Psychiatry 57, 1313-1323. doi: 10.1016/j.biopsych.2004.11.024

Fenstermaker, A. G., Prasad, A. A., Bechara, A., Adolfs, Y., Tissir, F., Goffinet, A., et al. (2010). Wnt/planar cell polarity signaling controls the anterior-posterior organization of monoaminergic axons in the brainstem. J. Neurosci. 30, 16053-16064. doi: 10.1523/JNEUROSCI.4508-10.2010

Fernando, C. V., Kele, J., Bye, C. R., Niclis, J. C., Alsanie, W., Blakely, B. D., et al. (2014). Diverse roles for Wnt7a in ventral midbrain neurogenesis and dopaminergic axon morphogenesis. Stem Cells Dev. 23, 1991-2003. doi: $10.1089 /$ scd.2014.0166

Flores, C., Manitt, C., Rodaros, D., Thompson, K. M., Rajabi, H., Luk, K. C., et al. (2005). Netrin receptor deficient mice exhibit functional reorganization of dopaminergic systems and do not sensitize to amphetamine. Mol. Psychiatry 10, 606-612. doi: 10.1038/sj.mp.4001607

Förster, E. (2014). Reelin, neuronal polarity and process orientation of cortical neurons. Neuroscience 269, 102-111. doi: 10.1016/j.neuroscience.2014.03.004

Fu, Y., Yuan, Y., Halliday, G., Rusznák, Z., Watson, C., and Paxinos, G. (2012). A cytoarchitectonic and chemoarchitectonic analysis of the dopamine cell groups in the substantia nigra, ventral tegmental area, and retrorubral field in the mouse. Brain Struct. Funct. 217, 591-612. doi: 10.1007/s00429-011-0349-2

Fujiyama, F., Sohn, J., Nakano, T., Furuta, T., Nakamura, K. C., Matsuda, W., et al. (2011). Exclusive and common targets of neostriatofugal projections of rat striosome neurons: a single neuron-tracing study using a viral vector. Eur. J. Neurosci. 33, 668-677. doi: 10.1111/j.1460-9568.2010.07564.x

Garcia-Peña, C. M., Kim, M., Frade-Pérez, D., Avila-González, D., Téllez, E., Mastick, G. S., et al. (2014). Ascending midbrain dopaminergic axons require descending GAD65 axon fascicles for normal pathfinding. Front. Neuroanat. 8:43. doi: 10.3389/fnana.2014.00043

Gasbarri, A., Packard, M. G., Sulli, A., Pacitti, C., Innocenzi, R., and Perciavalle, V. (1996). The projections of the retrorubral field A8 to the hippocampal formation in the rat. Exp. Brain Res. 112, 244-252. doi: 10.1007/BF00227643

Gates, M. A., Coupe, V. M., Torres, E. M., Fricker-Gates, R. A., and Dunnett, S. B. (2004). Spatially and temporally restricted chemoattractive and chemorepulsive cues direct the formation of the nigro-striatal circuit. Eur. J. Neurosci. 19, 831-844. doi: 10.1111/j.1460-9568.2004.03213.x

Gerfen, C. R. (1992). The neostriatal mosaic: multiple levels of compartmental organization. Trends Neurosci. 15, 133-139. doi: 10.1016/0166-2236(92) 90355-C

Gerfen, C. R., Herkenham, M., and Thibault, J. (1987). The neostriatal mosaic: II. Patch- and matrix-directed mesostriatal dopaminergic and non-dopaminergic systems. J. Neurosci. 7, 3915-3934.

Hernández-Montiel, H. L., Tamariz, E., Sandoval-Minero, M. T., and VarelaEchavarría, A. (2008). Semaphorins 3A, 3C, and $3 \mathrm{~F}$ in mesencephalic dopaminergic axon pathfinding. J. Comp. Neurol. 506, 387-397. doi: 10.1002/ cne. 21503

Hikosaka, O., Sesack, S. R., Lecourtier, L., and Shepard, P. D. (2008). Habenula: crossroad between the basal ganglia and the limbic system. J. Neurosci. 28, 11825-11829. doi: 10.1523/JNEUROSCI.3463-08.2008

Hua, Z. L., Jeon, S., Caterina, M. J., and Nathans, J. (2014). Frizzled3 is required for the development of multiple axon tracts in the mouse central nervous system. Proc. Natl. Acad. Sci. U.S.A. 111:E3005-14. doi: 10.1073/pnas.1406399111

Ikemoto, S. (2007). Dopamine reward circuitry: two projection systems from the ventral midbrain to the nucleus accumbens-olfactory tubercle complex. Brain Res. Rev. 56, 27-78. doi: 10.1016/j.brainresrev.2007.05.004

Joksimovic, M., Anderegg, A., Roy, A., Campochiaro, L., Yun, B., Kittappa, R., et al. (2009). Spatiotemporally separable shh domains in the midbrain define distinct dopaminergic progenitor pools. Proc. Natl. Acad. Sci. U.S.A. 106, 19185-19190. doi: 10.1073/pnas.0904285106

Kalia, L. V., and Lang, A. E. (2015). Parkinson's disease. Lancet 386, 896-912. doi: 10.1016/S0140-6736(14)61393-3

Kang, W. Y., Kim, S. S., Cho, S. K., Kim, S., Suh-Kim, H., Lee, Y. D., et al. (2010). Migratory defect of mesencephalic dopaminergic neurons in developing reeler mice. Anat. Cell Biol. 43:241. doi: 10.5115/acb.2010.43.3.241

Kawaguchi, Y., Wilson, C. J., and Emson, P. C. (1989). Intracellular recording of identified neostriatal patch and matrix spiny cells in a slice preparation preserving cortical inputs. J. Neurophysiol. 62, 1052-1068.

Kawano, H., Ohyama, K., Kawamura, K., and Nagatsu, I. (1995). Migration of dopaminergic neurons in the embryonic mesencephalon of mice. Dev. Brain Res. 86, 101-113. doi: 10.1016/0165-3806(95)00018-9

Khan, S., Stott, S. R. W., Chabrat, A., Truckenbrodt, A. M., SpencerDene, B., Nave, K.-A., et al. (2017). Survival of a novel subset of midbrain dopaminergic neurons projecting to the lateral septum is dependent on neurod proteins. J. Neurosci. 37, 2305-2316. doi: 10.1523/JNEUROSCI.241416.2016

Kolk, S. M., Gunput, R. A., Tran, T. S., van den Heuvel, D. M., Prasad, A. A., Hellemons, A, J., et al. (2009). Semaphorin 3F is a bifunctional guidance cue for dopaminergic axons and controls their fasciculation, channeling, rostral growth, and intracortical targeting. J. Neurosci. 29, 12542-12557. doi: 10.1523/ JNEUROSCI.2521-09.2009

La Manno, G., Gyllborg, D., Codeluppi, S., Nishimura, K., Salto, C., Zeisel, A., et al. (2016). Molecular diversity of midbrain development in mouse, human, and stem cells. Cell 167, 566-580.e19. doi: 10.1016/j.cell.2016.09.027

Lammel, S., Hetzel, A., Häckel, O., Jones, I., Liss, B., and Roeper, J. (2008). Unique properties of mesoprefrontal neurons within a dual mesocorticolimbic dopamine system. Neuron 57, 760-773. doi: 10.1016/j.neuron.2008. 01.022 
Lerner, T. N., Shilyansky, C., Davidson, T. J., Evans, K. E., Beier, K. T., Zalocusky, K. A., et al. (2015). Intact-brain analyses reveal distinct information carried by SNc dopamine subcircuits. Cell 162, 635-47. doi: 10.1016/j.cell.2015.07.014

Li, J., Duarte, T., Kocabas, A., Works, M., McConnell, S. K., and Hynes, M. A. (2014). Evidence for topographic guidance of dopaminergic axons by differential netrin-1 expression in the striatum. Mol. Cell. Neurosci. 61, 85-96. doi: 10.1016/j.mcn.2014.05.003

Lin, L., Rao, Y., and Isacson, O. (2005). Netrin-1 and Slit-2 regulate and direct neurite growth of ventral midbrain dopaminergic neurons. Mol. Cell. Neurosci. 28, 547-555. doi: 10.1016/j.mcn.2004.11.009

Manier, M., Cristina, N., Chatellard-Causse, C., Mouchet, P., Herman, J. P., and Feuerstein C. (1997). Striatal target-induced axonal branching of dopaminergic mesencephalic neurons in culture via diffusible factors. J. Neurosci. Res. 48, 358-371. doi: 10.1002/(SICI)1097-4547(19970515)48:4<358::AID-JNR8>3.0. $\mathrm{CO} ; 2-\mathrm{A}$

Marín, O., Valiente, M., Ge, X., and Tsai, L. H. (2010). Guiding neuronal cell migrations. Cold Spring Harb. Perspect. Biol. 2:a001834. doi: 10.1101/ cshperspect.a001834

Mason, H. A., Rakowiecki, S. M., Raftopoulou, M., Nery, S., Huang, Y., Gridley, T., et al. (2005). Notch signaling coordinates the patterning of striatal compartments. Development (Cambridge, England) 132, 4247-4258. doi: $10.1242 /$ dev.02008

Matsuda, W., Furuta, T., Nakamura, K. C., Hioki, H., Fujiyama, F., Arai, R., and Kaneko, T. (2009). Single nigrostriatal dopaminergic neurons form widely spread and highly dense axonal arborizations in the neostriatum. J. Neurosci. 29, 444-453. doi: 10.1523/JNEUROSCI.4029-08.2009

Milton, A. L., and Everitt, B. J. (2012). The persistence of maladaptive memory: addiction, drug memories and anti-relapse treatments. Neurosci. Biobehav. Rev. 36, 1119-1139. doi: 10.1016/j.neubiorev.2012.01.002

Morales, M., and Margolis, E. B. (2017). Ventral tegmental area: cellular heterogeneity, connectivity and behaviour. Nat. Rev. Neurosci. 18, 73-85. doi: $10.1038 / \mathrm{nrn} .2016 .165$

Morales, M., and Pickel, V. M. (2012). Insights to drug addiction derived from ultrastructural views of the mesocorticolimbic system. Ann. N. Y. Acad. Sci. 1248, 71-88. doi: 10.1111/j.1749-6632.2011.06299.x

Nishikawa, S., Goto, S., Yamada, K., Hamasaki, T., and Ushio, Y. (2003). Lack of reelin causes malpositioning of nigral dopaminergic neurons: evidence from comparison of normal andrelnrl mutant mice. J. Comp. Neurol. 461, 166-173. doi: $10.1002 /$ cne. 10610

Pacelli, C., Giguère, N., Bourque, M.-J., Lévesque, M., Slack, R. S., and Trudeau, L.-É. (2015). Elevated mitochondrial bioenergetics and axonal arborization size are key contributors to the vulnerability of dopamine neurons. Curr. Biol. 25, 2349-2360. doi: 10.1016/j.cub.2015.07.050

Panman, L., Papathanou, M., Laguna, A., Oosterveen, T., Volakakis, N., Acampora, D., et al. (2014). Sox6 and Otx2 control the specification of substantia nigra and ventral tegmental area dopamine neurons. Cell Rep. 8, 1018-1025. doi: 10.1016/j.celrep.2014.07.016

Passante, L., Gaspard, N., Degraeve, M., Frisén, J., Kullander, K., De Maertelaer, V., et al. (2008). Temporal regulation of ephrin/eph signalling is required for the spatial patterning of the mammalian striatum. Development (Cambridge, England) 135, 3281-3290. doi: 10.1242/dev. 024778

Pasterkamp, R. J., Kolk, S. M., Hellemons, A. J., and Kolodkin, A. L. (2007). Expression patterns of semaphorin7A and plexinC1 during rat neural development suggest roles in axon guidance and neuronal migration. BMC Dev. Biol. 7:98. doi: 10.1186/1471-213X-7-98

Pokinko, M., Moquin, L., Torres-Berrío, A., Gratton, A., and Flores, C. (2015). Resilience to amphetamine in mouse models of Netrin-1 haploinsufficiency: role of mesocortical dopamine. Psychopharmacology 232, 3719-3729. doi: 10.1007/s00213-015-4032-9

Poulin, J.-F., Zou, J., Drouin-Ouellet, J., Kim, K.-Y. A., Cicchetti, F., and Awatramani, R. B. (2014). Defining midbrain dopaminergic neuron diversity by single-cell gene expression profiling. Cell Rep. 9, 930-943. doi: 10.1016/j.celrep. 2014.10.008

Prakash, N., Puelles, E., Freude, K., Trümbach, D., Omodei, D., Di Salvio, M., et al. (2009). Nkx6-1 controls the identity and fate of red nucleus and oculomotor neurons in the mouse midbrain. Development 136, 2545-2555. doi: 10.1242/ dev.031781
Prensa, L., and Parent, A. (2001). The nigrostriatal pathway in the rat: a single-axon study of the relationship between dorsal and ventral tier nigral neurons and the striosome/matrix striatal compartments. J. Neurosci. 21, 7247-7260.

Prestoz, L., Jaber, M., and Gaillard, A. (2012). Dopaminergic axon guidance: which makes what? Front. Cell. Neurosci. 6:32. doi: 10.3389/fncel.2012. 00032

Raible, F., and Brand, M. (2004). Divide et impera-the midbrain-hindbrain boundary and its organizer. Trends Neurosci. 27, 727-734. doi: 10.1016/j.tins. 2004.10.003

Renier, N., Wu, Z., Simon, D. J., Yang, J., Ariel, P., and Tessier-Lavigne, M. (2014). iDISCO: a simple, rapid method to immunolabel large tissue samples for volume imaging. Cell 159, 896-910. doi: 10.1016/j.cell.2014. 10.010

Richards, A. B., Scheel, T. A., Wang, K., Henkemeyer, M., and Kromer, L. F. (2007). EphB1 null mice exhibit neuronal loss in substantia nigra pars reticulata and spontaneous locomotor hyperactivity. Eur. J. Neurosci. 25, 2619-2628. doi: 10.1111/j.1460-9568.2007.05523.x

Robinson, T. E., and Kolb, B. (2004). Structural plasticity associated with exposure to drugs of abuse. Neuropharmacology 47, 33-46. doi: 10.1016/j.neuropharm. 2004.06.025

Schein, J. C., Hunter, D. D., and Roffler-Tarlov, S. (1998). Girk2 expression in the ventral midbrain, cerebellum, and olfactory bulb and its relationship to the murine mutationweaver. Dev. Biol. 204, 432-450. doi: 10.1006/dbio.1998.9076

Schmidt, E., Brignani, S., Adolfs, Y., Lemstra, S., Demmers, J., Vidaki, M., et al. (2014). Subdomain-mediated axon-axon signaling and chemoattraction cooperate to regulate afferent innervation of the lateral habenula. Neuron 83372-83387. doi: 10.1016/j.neuron.2014.05.036

Sharaf, A., Rahhal, B., Spittau, B., and Roussa, E. (2015). Localization of reelin signaling pathway components in murine midbrain and striatum. Cell Tissue Res. 359, 393-407. doi: 10.1007/s00441-014-2022-6

Shults, C. W., Hashimoto, R., Brady, R. M., and Gage, F. H. (1990). Dopaminergic cells align along radial glia in the developing mesencephalon of the rat. Neuroscience 38, 427-436. doi: 10.1016/0306-4522(90) 90039-7

Sieber, B.-A., Kuzmin, A., Canals, J. M., Danielsson, A., Paratcha, G., Arenas, E., et al. (2004). Disruption of EphA/ephrin-A signaling in the nigrostriatal system reduces dopaminergic innervation and dissociates behavioral responses to amphetamine and cocaine. Mol. Cell. Neurosci. 26, 418-428. doi: 10.1016/j.mcn. 2004.03.009

Simeone, A., Di Salvio, M., Di Giovannantonio, L. G., Acampora, D., Omodei, D., and Tomasetti, C. (2011). The role of Otx2 in adult mesencephalic-diencephalic dopaminergic neurons. Mol. Neurobiol. 43, 107-113. doi: 10.1007/s12035-0108148-y

Snyder-Keller, A. M. (1991). Development of striatal compartmentalization following pre- or postnatal dopamine depletion. J. Neurosci. 11, 810-821.

Stamatakis, A. M., Jennings, J. H., Ung, R. L., Blair, G. A., Weinberg, R. J., Neve, R. L., et al. (2013). A unique population of ventral tegmental area neurons inhibits the lateral habenula to promote reward. Neuron 80, 1039-1053. doi: 10.1016/j.neuron.2013.08.023

Thompson, L., Barraud, P., Andersson, E., Kirik, D., and Björklund, A. (2005). Identification of dopaminergic neurons of nigral and ventral tegmental area subtypes in grafts of fetal ventral mesencephalon based on cell morphology, protein expression, and efferent projections. J. Neurosci. 25, 6467-6477. doi: 10.1523/JNEUROSCI.1676-05.2005

Torigoe, M., Yamauchi, K., Tamada, A., Matsuda, I., Aiba, A., Castellani, V., et al. (2013). Role of neuropilin-2 in the ipsilateral growth of midbrain dopaminergic axons. Eur. J. Neurosci. 37, 1573-1583. doi: 10.1111/ejn. 12190

Van Battum, E. Y., Brignani, S., and Pasterkamp, R. J. (2015). Axon guidance proteins in neurological disorders. Lancet Neurol. 14, 532-546. doi: 10.1016/ S1474-4422(14)70257-1

Van den Heuvel, D. M. A., and Pasterkamp, R. J. (2008). Getting connected in the dopamine system. Prog. Neurobiol. 85, 75-93. doi: 10.1016/j.pneurobio.2008. 01.003

van der Kooy, D., and Fishell, G. (1987). Neuronal birthdate underlies the development of striatal compartments. Brain Res. 401, 155-161. doi: 10.1016/ 0006-8993(87)91176-0 
Verney, C. (1999). Distribution of the catecholaminergic neurons in the central nervous system of human embryos and fetuses. Microsc. Res. Tech. 46, 24-47. doi: 10.1002/(SICI)1097-0029(19990701)46:1<24::AID-JEMT3<3.0. $\mathrm{CO} ; 2-\mathrm{E}$

Walsh, J. J., and Han, M. H. (2014). The heterogeneity of ventral tegmental area neurons: projection functions in a mood-related context. Neuroscience 282, 101-108. doi: 10.1016/j.neuroscience.2014. 06.006

Watabe-Uchida, M., Zhu, L., Ogawa, S. K., Vamanrao, A., and Uchida, N. (2012). Whole-brain mapping of direct inputs to midbrain dopamine neurons. Neuron 74, 858-873. doi: 10.1016/j.neuron.2012.03.017

Winterer, G., and Weinberger, D. R. (2004). Genes, dopamine and cortical signalto-noise ratio in schizophrenia. Trends Neurosci. 27, 683-690. doi: 10.1016/j. tins.2004.08.002

Xu, B., Goldman, J. S., Rymar, V. V., Forget, C., Lo, P. S., Bull, S. J., et al. (2010). Critical roles for the netrin receptor deleted in colorectal cancer in dopaminergic neuronal precursor migration, axon guidance, and axon arborization. Neuroscience 169, 932-949. doi: 10.1016/j.neuroscience.2010. 05.025

Yamauchi, K., Mizushima, S., Tamada, A., Yamamoto, N., Takashima, S., and Murakami, F. (2009). FGF8 signaling regulates growth of midbrain dopaminergic axons by inducing semaphorin 3F. J. Neurosci. 29, 4044-4055. doi: 10.1523/JNEUROSCI.4794-08.2009

Yang, S., Edman, L. C., Sánchez-Alcañiz, J. A., Fritz, N., Bonilla, S., Hecht, J., et al. (2013). Cxcl12/Cxcr4 signaling controls the migration and process orientation of A9-A10 dopaminergic neurons. Development (Cambridge, England) 140, 4554-4564. doi: 10.1242/dev.098145

Yue, Y., Widmer, D. A. J., Halladay, A. K., Cerretti, D. P., Wagner, G. C., Dreyer, J.-L., et al. (1999). Specification of distinct dopaminergic neural pathways: roles of the eph family receptor EphB1 and ligand Ephrin-B2. J. Neurosci. 19, 2090-2101.

Conflict of Interest Statement: The authors declare that the research was conducted in the absence of any commercial or financial relationships that could be construed as a potential conflict of interest.

Copyright (C) 2017 Brignani and Pasterkamp. This is an open-access article distributed under the terms of the Creative Commons Attribution License (CC BY). The use, distribution or reproduction in other forums is permitted, provided the original author(s) or licensor are credited and that the original publication in this journal is cited, in accordance with accepted academic practice. No use, distribution or reproduction is permitted which does not comply with these terms. 